\title{
Novidades taxonômicas em Aldama (Asteraceae-Heliantheae)
}

\author{
Taxonomical novelties in Aldama (Asteraceae-Heliantheae)
}

\author{
Mara Angelina Galvão Magenta ${ }^{1,2}$ \& José Rubens Pirani ${ }^{2}$
}

\begin{abstract}
Resumo
Estudos recentes de dados moleculares evidenciaram que as espécies sul-americanas tradicionalmente tratadas em Viguiera Kunth deveriam ser transferidas para Aldama La Llave. Seguindo essa nova circunscrição, o estudo taxonômico das 35 espécies de Aldama do Brasil demonstra que são ainda necessárias três novas combinações de nomes de espécies e duas de nomes de variedades, além do reconhecimento de uma nova variedade, 20 sinonimizações e 25 lectotipificações.
\end{abstract}

Palavras-chave: Brasil, Compositae, Helianthinae, Rhysolepis, Viguiera.

\begin{abstract}
Recent studies using molecular data showed that the species traditionally treated as Viguiera Kunth in South America should be transferred to Aldama La Llave. After carrying out a taxonomic study of the 35 Brazilian species of Aldama, we propose three new combinations for binomials and two for varieties, plus a new variety, 20 new synonyms and 25 lectotypifications.
\end{abstract}

Key words: Brazil, Compositae, Helianthinae, Rhysolepis, Viguiera.

\section{Introdução}

Vários autores (Robinson 1977; Schilling \& Jansen 1989; Karis 1993; Schilling \& Panero 1991, 2002, 2011) têm apontado o polifiletismo de Viguiera Kunth senso Blake (1918). Análises cladísticas e, principalmente, a elaboração de filogenias baseadas em dados moleculares, levaram ao desmembramento de Viguiera (Yates 1979; Schilling \& Jansen 1989; Schilling \& Panero 1996a, 1996b, 2002; Magenta \& et al. 2010) em gêneros menores. Com base nas observações de Robinson (1977), que notou a existência de tricomas nos filetes de Viguiera dentata (Cav.) Spreng., a espécie-típica do gênero, e percebendo que nenhum dos sinônimos apresentados por Blake (1918) seria aplicável, Robinson \& Moore (2004) sugeriram a transferência das plantas sul-americanas para Rhysolepis S. F. Blake. No entanto, nas análises filogenéticas baseadas em morfologia efetuadas por Magenta (2006), Aldama La Llave (1824) emergiu como grupo-irmão de Rhysolepis S.F. Blake (1917) e, por prioridade, seria o nome corretamente aplicado. Aldama, que até então era representado apenas duas espécies mesoamericanas, apresenta algumas diferenças morfológicas em relação às plantas sul-americanas tradicionalmente incluídas em Viguiera. Embora compartilhe com o segundo a presença de capítulos com flores liguliformes amarelas e neutras e flores do disco perfeitas, férteis, com corola tubulosa claramente dividida em tubo e limbo, Aldama possui páleas do receptáculo das flores periféricas do disco transversalmente corrugadas, com base acentuadamente gibosa e ápice pungente e as cipselas das flores da periferia do disco são conspicuamente assimétricas, com pápus facilmente destacável. As plantas da América do Sul possuem receptáculo com páleas naviculares com ápice agudo, ou às vezes obtuso ou truncado, que envolvem apenas parcialmente a flor, as cipselas são simétricas com pápus persistente na grande maioria das espécies, incluindo todas as do Brasil (Magenta et al. 2010).

\footnotetext{
${ }^{1}$ Universidade Santa Cecília, R. Oswaldo Cruz 277, Boqueirão, 11045-90, Santos, SP, Brasil.

${ }^{2}$ Universidade de São Paulo, R. do Matão, Inst. Biociências, Depto. Botânica, Trav. 14, 321, 05508-900, São Paulo, SP, Brasil.

${ }^{3}$ Autor para correspondência: maramagenta@unisanta.br
} 
Com o objetivo de fornecer uma estimativa completa das linhagens derivadas da subtribo Helianthinae, à qual pertence Aldama, Shilling \& Panero (2011) efetuaram uma análise combinando os dados resultantes dos estudos da variação nas sequências de ITS de Helianthinae (Schilling \& Panero 2002, 2010) com informações de uma matriz de dados parcial do espaçador externo transcrito (ETS), análise de DNA plastidial e de dados morfológicos. Os autores propuseram uma revisão da classificação genérica de Helianthinae onde Viguiera passou a ser constituído apenas pela espécie-típica, $V$. dentata (Cav.) Spreng. e as espécies sul-americanas foram transferidas para Aldama La Llave, expandindo o gênero para 112 espécies, distribuídas do sudoeste da América do Norte e México até a América do Sul. Entretanto, esses autores deixaram de apresentar combinações referentes a algumas espécies do gênero. $\mathrm{O}$ estudo taxonômico das espécies brasileiras do grupo, realizado por Magenta (2006), revelou 35 espécies no país e apontou a necessidade de quatro novas combinações de nomes de espécies em Aldama (uma já publicada em Bombo et al., 2012 e as demais aqui apresentadas) e duas de nomes de variedades, além do reconhecimento de uma nova variedade e proposição de 25 lectotipificações e 20 sinonimizações novas. Este trabalho tem por objetivos prover essas atualizações nomenclaturais em Aldama, apresentando citação dos protólogos e tipos e incluindo as lectotipificações necessárias. Também é nosso objetivo apresentar comentários sobre a distribuição geográfica e variabilidade morfológica de cada espécie aqui tratada, visando sustentar e justificar explicitamente as circunscrições taxonômicas e as decisões efetuadas.

\section{Material e Métodos}

Este estudo baseia-se na filogenia obtida por Schilling \& Panero (2011) e nos dados do tratamento taxonômico feito por Magenta (2006). Os dados sobre o país ou o estado onde foi realizada a coleta do tipo, quando não existentes no protólogo, mas passíveis de conclusão, foram citados entre colchetes; nos casos em que não havia referências que permitissem isso, a informação foi omitida. A sigla dos herbários que tiveram os materiais-tipo examinados é seguida por ponto de exclamação (!); os materiais dos quais se avaliou imagens digitais dos tipos nomenclaturais têm a sigla de herbário seguida de asterisco (*); os herbários cujos espécimes-tipo são mencionados em bibliografia, e não foram examinados durante este trabalho, são representados exclusivamente pela sigla. A estrutura dos estames é descrita segundo Robinson \& King (1977). Seguindo cada combinação ou sinonimização novas aqui propostas, apresenta-se a listagem total do material examinado apenas no caso das espécies conhecidas por até 10 registros; nos casos de espécies com muitas coletas, apresenta-se uma seleção de alguns dos materiais examinados, representativa da distribuição da espécie. A sequência das espécies e dos sinônimos, dentro de cada tópico, segue ordem alfabética.

\section{Resultados e Discussão}

Combinações, seus sinônimos novos e suas lectotipificações

Aldama anchusifolia var. imarginata (S.F. Blake) Magenta \& Pirani, comb. nov. Leighia immarginata DC., Prodr. 5: 581. 1836. Viguiera anchusaefolia var. immarginata (DC.) S. F. Blake, Contr. Gray Herb. 54. 1918. Viguiera immarginata (DC.) Herter, Revista Sudamer. Bot. 7 (6/8): 236. 1943. Tipo: BRÉSIL. [RIO GRANDE DO SUL]: Province de Rio-Grande, Herb. Imp. Brés. 1052 (holótipo: P!; fotografia do holótipo: K!, SPF!). Leighia stenophylla Hook. \& Arn., London J. Bot. 3: 313. 1841. Viguiera stenophylla (Hook. \& Arn.) Griseb., Abh. Königl. Ges. Wiss. Göttingen 24: 193. 1879 [Symb. Arg.: 193. 1879]. Tipo: [URUGUAI]. BUENOS AYRES and MONTEVIDEO (Lectótipo aqui designado: Tweedie 870 : K!; fotografia do lectótipo: K!, SPF!).

Helianthus angustifolius Spreng. ex Baker in Mart. \& Eichler, Fl. bras. 6(3): 221. 1884, nom. nud. pro syn. Helianthus montevidensis Spreng. ex Arechav., Anales Mus. Nac. Montevideo VI (Fl. Urug. III). 1908.

Material selecionado: ARGENTINA. BUENOS AIRES: La Plata, Elijalde, junto à via férrea, 2.IV.1929, fr., A.L. Cabrera 779 (SP). BRASIL. PARANÁ: Laranjeiras do Sul, $85 \mathrm{~km} \mathrm{SW}$ de Guarapuava, Fazenda da Reserva, Rio Reseva, 13.III.1967, fl. e fr., J.C. Lindeman \& S. Haas 4807 (K, MBM). RIO GRANDE DO SUL: Esmeralda, 23.II.1983, fl., G. Hiltll 1410 (HAS). Faxinal [do Soturno], em beira da estrada, 930 m.a.m., 10.III.2000, fl. e fr., $R$. Wasum 524 (HUCS, MBM). Ijuí, 14.I.1977, fl., J.R. Mattos \& N.F. Mattos 16652 (HAS). Júlio de Castilhos, Passo do Felício, ca. $15 \mathrm{~km}$ a SE da cidade, 15.II.1994, fl., $C$. Mondin 830 (ICN); estrada para Santo Antão, no Passo do Felício, a $1 \mathrm{~km}$ da BR $158,29^{\circ} 16^{\prime} 06,1^{\prime \prime} \mathrm{S}, 53^{\circ} 39^{\prime} 38,4^{\prime \prime} \mathrm{W}$, 491 m.a.m., 25.I.2003, fl. e fr., M. Magenta \& C. Mondin 533 (SPF). Porto Alegre, Morro do Osso, 17.I.1996, fl., 
R.S. Rodrigues 56 (ICN). Santo Ângelo, 17.XI.1952, fl., B. Rambo s.n. (PACA 53004). São Francisco de Paula, rodovia RS 20, Serra Geral, entre São Francisco de Paula e Tainhas, 29²5'07,5”S, 50²9'01,2”W, 941 m.a.m., 10.IV.2003, fl., M. Magenta \& L.R. Lima 587 (SPF). São José dos Ausentes, Cascata da Rocinha, 10.XII.1994, fl., N.I. Matzenbacher et al. (ICN 106240). Vacaria, margem do Rio Pelotas, Encanados, II.1997, fl., M. Sobral et al. 8228 (MBM). SANTA CATARINA: Curitibanos, $10 \mathrm{~km}$ oeste de Curitibanos, na estrada para Campos Novos, 850 m.a.m., 9.II.1957, fl., L.B. Smith \& R. Klein 11128 (RB). São Joaquim, Invernadinha, Fazenda Velha, III.1953, fl., J.R. Mattos 1297 (HAS). URUGUAI. MONTEVIDEO: III.1875, fl., Arechavelata 4115 (K); Paysandú Tacuarembó, 3.III.1991, fl., V. Eden 15672 (CTES, MBM). Soriano, Juan Jackson para Soriano, IV.1941, fl., B. Rosengurtt PE 4776 (LP, PACA).

Aldama anchusifolia destaca-se por apresentar ramos aéreos delicados, flexíveis, ligados a um caule subterrâneo fortemente espessado e raízes de tuberosidade fusiforme. Ao descrever a espécie no gênero Viguiera, Blake (1918) distinguiu duas variedades, com base na forma das folhas: a que chamou de var. genuina, com folhas de lâmina estreitamente oblonga ou oblongo-lanceolada e a var. immarginata, com folha de lâmina linear ou oblongo-linear. O exame de vários espécimes herborizados mostrou que é possível delimitar as duas variedades, tornando necessária a combinação acima.

Apesar de haver dois materiais coletados por Tweedie na mesma exsicata (Twedie 870 e 875), além de mais três plantas de coletores e locais diferentes, o lectótipo de Leighia stenophylla foi escolhido por conter junto a ele a etiqueta manuscrita por Tweedie, mencionando Montevideo como local de coleta.

Aldama corumbensis (Malme) Magenta \& Pirani, comb. nov. Viguiera corumbensis Malme, Ark. Bot. 24A (8): 45. 1931. Tipo: BRASIL. MATO GROSSO DO SUL: Corumbá, in silva clara, loco interdum inundato, 11.IV.1903, Malme II. s.n. (lectótipo aqui designado: S! [S 04-931]); fotografia do lectótipo: K!, SPF!; isolectótipos: S! (R 6475 e S 04 -925).

Aldama hatschbachii (H. Rob. \& A. J. Moore) E. E. Schill. \& Panero, Bot. J. Linn. Rhysolepis hatschbachii H. Rob. \& A. J. Moore, Proc. Biol. Soc. Washington 117(3): 438. 2004. Soc. 167: 323. 2011. Tipo: BRASIL. MATO GROSSO DO SUL: Rodovia Bonito - Campo dos Índios, próximo de Três Morros (Mun. Bonito); encosta do morro; solo calcário, 10.III.2003, G. Hatschbach et al. 74469 (holótipo: $\mathrm{MBM}^{*}$; isótipo: $\mathrm{US}^{*}$ ). syn. nov.
Material examinado: BRASIL. MATO GROSSO DO SUL: Corumbá, caminho de Urucum, IV.1963, fl. e fr., G.M. Barroso s.n. (PEL 5138, RB 117480). Miranda, Fazenda Lagoão Fechado, 18.III.2003, fl. e fr., G. Hatschbach et al. 74900 (MBM, SPF).

Espécie encontrada apenas no oeste do estado de Mato Grosso do Sul, pode ser reconhecida pelas folhas alternas levemente discolores com pecíolo de 2-4 $\mathrm{mm}$ de comprimento, alado, lâmina 5-14 × 1-4,5 cm, elíptica a elípticolanceolada. É morfologicamente próxima de Aldama helianthoides (L. Rich.) E. E. Schill. \& Panero, uma espécie andina, diferenciando-se pelas brácteas involucrais foliáceas apenas no ápice, pelas flores do raio em número de 10 a 12 e pelas cipselas trigonais. A. helianthoides possui brácteas involucrais inteiramente foliáceas, raio com 14 a 20 flores e cipselas compressas, não trigonais.

Justifica-se a escolha do lectótipo porque o material S 04-931 contém as informações manuscritas por Malme e citadas no protólogo.

Aldama megapotamica (Malme) Magenta \& Pirani, comb. nov. Viguiera megapotamica Malme, Ark. Bot. 24A (6): 68. 1931. Tipo: BRASIL. RIO GRANDE DO SUL: Cachoeira, in campo aprico, 5-I-1902, Malme (II) 922 a [lectótipo UPS!; isolectótipo GH!, designados por Mondin (2006)]. Material examinado: BRASIL. RIO GRANDE DO SUL: Arroio dos Ratos, rodovia BR $290 \mathrm{~km} \mathrm{159,7,} \mathrm{sentido} \mathrm{Arroio}$ dos Ratos - Cachoeira do Sul, 3006'33,4’'S, 5148'27,6”W, 94 m.a.m., 21.I.2003, fl. e fr., M. Magenta \& C. Mondin 502 (SPF); km 159,5, 3006'33,7'S, 5148'28,1'W, 76 m.a.m., 12.IV.2003, fl. e fr., M. Magenta et al. 595 (K, SPF, TEX). Cachoeira, in campo aprico, 3.I.1902, Malme II. 522 [922 - veja comentários] (GH, LP, R!, S!, PS); 20.I.1902, fl., (GH*, S!), Cachoeira do Sul, 18.II.1948, fl., PalaciosCuezzo 1151 (LP). estrada Cachoeira do Sul - Santana de Boa Vista, IV.1995, fl., M. Sobral \& Jarenkow 7874 (ICN); Santa Maria, estrada Silvicultura - Santa Maria, 2.I.1956, fl., O. Camargo 125 (PACA). 10.IV.1956, fl., O. Camargo 492 (PACA). SANTA CATARINA: Curitibanos, $1 \mathrm{~km}$ de Lebon Regis, 900 m.a.m., 16.III.1957, fl. e fr., L.B. Smith \& R. Klein 12199 (RB).

Restrita aos estados de Rio Grande do Sul e Santa Catarina; a espécie destaca-se pela presença de lâmina linear-filiforme com 30-80 × 1-1,5 mm. É morfologicamente semelhante a Aldama anchusifolia var. immarginata (S.F. Blake) Magenta \& Pirani (combinação proposta logo acima), que apresenta folhas lineares a oblongolineares, paracládios flexuosos, capítulos com 3-5,5 cm diâm., escamas do pápus com 1-1,7 mm de alt. e ápice fimbriado; no entanto, se diferencia 
por apresentar folhas linear-filiformes, paracládios eretos, capítulos com 2-2,5 cm diâm. e escamas do pápus menores, com $0,7-1 \mathrm{~mm}$ alt., unidas até a metade e ápice eroso.

Aldama paranensis (Malme) Magenta \& Pirani, comb. nov. Viguiera paranensis (Malme) Santos, Rodriguésia 42/44 (68/70): 47. 1992. Aspilia paranensis Malme Kong. Swensk. Vetensk Akad. Handl. 3a sér. 12 (2): 88. 1933. Wedelia paranensis (Malme) B. Turner. Phytologia 72(5): 393. 1992. Tipo: BRASIL. PARANÁ: 19.X.1914, Turma 23 n.15646 [Paraná: 23 Turma, in Campo, Dusén 15646 (BM!, $\left.\mathrm{S}^{*}\right)$ ] (lectótipo aqui designado: $\mathrm{S}^{*}$; fotografia do lectótipo: K!, SPF!; isolectótipos: BM!, G). Material examinado: BRASIL. PARANÁ: Ponta Grossa, 850 m.a.m., 28.XI.1946, fl., Maack (MBM, RB 74710). IX.1950, fl., J. Vidal \& Araújo III-228 (R). Lagoa Dourada - Furnas, 7.XI.1987, fl., P.M. Araki s.n. (HUEPG 3498), P.M. Araki (HUEPG 3506). município indefinido, 19.X.1914, fl., Dusén 15637 (K).

Evidencia-se pelo hábito decumbente e por ser uma das poucas espécies do gênero com raízes adventícias sem tuberosidades. É semelhante à Aldama nudicaulis (Baker) E.E. Schill. \& Panero, diferenciando-se pela presença de flores do disco com limbo de base uniforme e tubo com cerca de $1,5 \mathrm{~mm}$ de altura, além de anteras terminando na base do colar da antera $A$. nudicaulis tem flores do disco com limbo não uniforme, de base urceolada e tubo menor, variando de 0,5 a $1 \mathrm{~mm}$ altura, além de anteras terminando acima da base do colar da antera.

Santos (1992) referiu o material de Estocolmo como holótipo, sem discriminar as exsicatas; por isso houve a necessidade de lectotipificação.

Aldama tuberosa var. guaranitica (Chodat) Magenta, comb. nov. Viguiera tuberosa var. guaranitica (Chodat) Hassl. Viguiera guaranitica Chodat, Bull. Herb. Boissier ser. 2 (3): 724. 1903. Tipo: PARAGUAY. Ad marginem silvae in regione cursus superioreis fluminis Apa, 1901-02, Hassler 7667 (lectótipo aqui designado: $\mathrm{G}^{*}$; isolectótipos: BM!, frag. GH).

Viguiera tuberosa var. guaranitica f. angustifolia Hassl., Repert. Sp. Nov. Regni Veg. 14: 275. 1916. Tipo: PARAGUAY. Hassler 8349 1.c. (lectótipo aqui designado: $\mathrm{G}^{*}$; isolectótipos: BM!, NY).

Viguiera tuberosa var. guaranitica f. major Hassl., Repert. Sp. Nov. Regni Veg. 14: 275. 1916: 276. Tipo: PARAGUAY. Hassler 7667 (lectótipo aqui designado: $\mathrm{G}^{*}$; isolectótipo: $\mathrm{BM}$ !).
Viguiera tuberosa var. guaranitica f. scaberula Hassl., Repert. Sp. Nov. Regni Veg. 14: 275. 1916: 276. Tipo: PARAGUAY. [MISIONES]: Caballero Cué, Fiebrig n ${ }^{\circ} 4844^{\prime}$ (holótipo: G*).

Material selecionado: ARGENTINA. CORRIENTES: Formosa, Patiño, Ruta 81, 15 km NW de Las Lomitas, 26.XI.1994, fl., A. Krapovickas \& C.L. Cristóbal 46413 (CTES). Santo Tomé, Estancia Garruchos, 6.II.1972, fl., A. Krapovickas et al. 21089 (CTES). MISIONES: Canonelaria, Picda San Martin, 16.IV.1947, G.J. Sehwarz 4492 (R). San Ignácio, Santo Pipo, 4.XI.1947, fl., G.J. Sehwarz 5100 (LP). BRASIL. MATO GROSSO: Primavera, Alto Paraguai, 10.XII.1956, fl., A.L. Woclston 766 (SP, SPF). RIO GRANDE DO SUL: Manoel Viana, Cerro do Negro, 16.XI.2002, fl., C. Mondin \& A. Iob 2825 (HASU, SPF). Santana do Livramento,

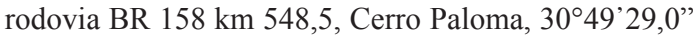
55²0'54,0”W, 132 m.a.m., 23.I.2003, fl., M. Magenta \& C. Mondin 512 (SPF). SANTA CATARINA: Capinzal, estrada de Capinzal, 700 m.a.m., 30.X.1963, fl., R. Klein 4297 (RB). PARAGUAI. [CORDILLERA]: In campo pr. Valenzuela, Jan. Hassler $8970\left(\mathrm{G}^{*}\right)$. I.1902, Hassler 8349 (G*). SAN PEDRO: Gran Chaco, in campis siccis pr. Santa Rita, Hassler $\mathrm{n}^{\circ} 2652\left(\mathrm{G}^{*}\right)$. Hassler $2652 a$ $\left(\mathrm{G}^{*}\right)$. Flossdorf $\mathrm{n}^{\circ} 151\left(\mathrm{G}^{*}\right)$.

Aldama tuberosa pode ser reconhecida pelas folhas longas e estreitas (lâmina 4-12 $\times 0,25-1,5 \mathrm{~cm})$ e pelas brácteas involucrais em 2-3 séries levemente apressas na floração, fortemente caniculadas na base. Embora seja impraticável a manutenção da maioria das categorias infraespecíficas propostas por Hassler (1916) o estudo de Magenta (2006) demonstra a consistência de variedades. Enquanto a variedade típica possui folhas oblongas a estreitamente oblongas, A. tuberosa var. guaranitica apresenta folhas elípticas a estreitamente elípticas. Tais caracteres diferenciais podem indicar divergências genéticas populacionais expressivas ou até processos de especiação incipientes.

\section{Variedade nova}

Aldama gardneri var. ovatifolia Magenta, var. nov. Tipo: BRASIL. GOIÁS: Santo Antônio do Descoberto, morro a $1 \mathrm{~km}$ em direção a Cidade Eclética, 9.IV.1984, B.A.S. Pereira 994 (holótipo: IBGE!; isótipos: HEPH!, RB!, SP!, US!).

A Aldama gardneri (Baker) E. E. Schill. \& Panero var. gardneri affinis sed foliis et bracteolis ovatis ad late ovatis involucri bracteis cum longa cilia differt.

Erva a subarbusto com resina, 1-2,5 m alt., ramos aéreos eretos, cilíndricos, escabrosos, híspidos a setosos, entrenós $0,8-15 \mathrm{~mm}$ compr.; 
caule subterrâneo com raízes adventícias tuberosas na porção mediana. Folhas verde-claras a discolores, 1-2 pares basais opostos, as superiores alternas; pecíolo 0,3-1,2 mm compr.; lâmina 3,5-12 × 0,8-4 $\mathrm{cm}$ oval, base arredondada, obtusa ou atenuada, ápice agudo, mucronulado, inteira ou esparsamente denteada a esparsamente serreada na porção superior, cartácea, nervação acródroma basal a suprabasal, imperfeita a perfeita, 3 nervuras principais, face adaxial esparsa a densamente estrigosa, tricomas tectores 2-celulares com bossas, base cilíndrica levemente apressa, cercada por 1-2 séries de células, face abaxial esparsa a densamente estrigosa a vilosa, tricomas tectores 2-3-celulares, com bossas, às vezes com tricomas glandulares. Sinflorescência botrióide ou tirsóide, $20-50 \mathrm{~cm}$ alt., paracládios eretos a flexuosos, superiores terminando acima do capítulo terminal ou raramente próximo a ele, estreitamente canaliculados, estrigosos, com bractéolas foliáceas ovais a largamente ovais, $1^{\text {a }}$ ordem 10-30 cm compr., $2^{\mathrm{a}}$ ordem 4,5-8 cm compr.; pedúnculo terminal $1,5-11 \mathrm{~cm}$ compr. Capítulos 3-4 cm diâm., radiados, invólucro 8-12 mm diâm., campanulado a semigloboso, subtendido por 1-2 bractéolas 3-10 mm compr., ovais, estrigosas, brácteas involucrais reflexas na floração, 4-5 séries, oblongas, largamente oblongas ou lanceoladas, base estriada, 3 nervuras levemente destacadas, foliáceas em 1/3 superior, ápice agudo mucronado, ciliadas, cílios longos, coriáceas, face adaxial glabra a híspida, com ou sem glândulas, $1^{\mathrm{a}}$ série 4-5(-10) $\mathrm{mm}$ alt., face abaxial estrigosa a vilosa na porção superior, $2^{\mathrm{a}}$ série $6-8(-11) \mathrm{mm}$ alt., face abaxial estrigilosa na porção superior, $3^{\mathrm{a}}$ e $4^{\mathrm{a}}$ séries $8-13$ $\mathrm{mm}$ alt., face abaxial esparsamente estrigilosa na porção superior; receptáculo levemente convexo, páleas $7-10 \mathrm{~mm}$ alt., oblongas a levemente obovais, ápice expandido truncado ou obtuso, geralmente mucronado, 8, 10 ou 12 nervuras, a principal estrigosa, carena estreita estrigosa. Flores do raio 12-16, em um verticilo, corola 9-12 × 2-3 mm, tubo 1,5-2 mm alt., limbo oblongo, ápice curtamente 2-partido, face adaxial glabra, face abaxial com 8-10 nervuras estrigilosas; tubo estrigiloso a estrigoso; flores do disco 80-150, corola 6-7 $\mathrm{mm}$ alt., tubo $1-1,2 \mathrm{~mm}$ alt., face externa estrigilosa, antera de base curtamente sagitada, terminando acima ou na base do colar da antera, estilete com alargamento basal fusiforme, estilopódio $0,16-0,18 \times 0,38-0,40 \mathrm{~mm}$. Cipselas 3-4,5 mm alt., estreitamente obovóides, estriadas, jovens seríceas, maduras glabrescentes, carpopódio delgado, pápus estramíneo a amarelado com manchas vináceas, 1-2-aristado, aristas marginais iguais a desiguais $1,5-2,5 \mathrm{~mm}$ alt., livres, delicadas, estreitamente triangulares, margem lacerada, escamas 3-4 pares, 0,7-1,5 mm alt., unidas até próximo ao ápice lacerado.

Material examinado: BRASIL. GOIÁS: Itiquira, 16.III.1980, fl. e fr., A.E.H. Salles 160 (HEPH, IBGE); Luziânia, estrada para Santo Antonio do Descoberto, 27.III.1980, fl., E.P. Heringer 17691 (HEPH, IBGE); Santo Antonio do Descoberto, estrada de terra entre Santo Antonio e Cidade Eclética, $13 \mathrm{~km}$ de Santo Antonio, margem direita, $15^{\circ} 53^{\prime} \mathrm{S}, 48^{\circ} 19^{\prime} \mathrm{W}, 1120$ m.a.m., 24.IV.1998, fl. e fr., F.B. Costa 81 (SPF, SPFR).

Esta é uma planta resinífera encontrada no sudoeste de Goiás, com capítulos de 3-4 cm de diâmetro e brácteas involucrais em 3-4 séries. Enquanto a variedade típica apresenta folhas com lâmina oblonga a largamente oblonga, elíptica ou oval-lanceolada e brácteas involucrais com cílios curtos, a nova variedade tem folhas e bractéolas ovais a largamente ovais e brácteas involucrais com cílios longos.

\section{Recircunscrições taxonômicas, seus sinônimos novos e suas lectotipificações}

Aldama aspilioides (Baker) E. E. Schill. \& Panero. Viguiera aspilioides Baker in Mart., Fl. bras. 6(3): 228. 1884. Wedelia aspilioides (Baker) B. L. Turner, Phytologia 72(5): 391. 1992. Rhysolepis aspilioides (Baker) H. Rob. \& A. J. Moore, Proc. Biol. Washington 117(7): 425. 2004. Tipo: BRASIL: Facienda de Santa Anna. Sello 669 [holótipo provavelmente no herbário B, destruído] (neótipo aqui designado: Sello s.n. K! esboço; fotografia do neótipo: SPF!).

Material selecionado: BRASIL. PARANÁ: Colombo, Rio Canguiri, 3.X.1967, fl., G. Hatschbach 17257 (LP, MBM); Palmeira, Rio do Salto, 10.XI.1951, fl., G. Hatschbach 2693 (MBM). Palhoça, Ponta do Papagaio, 22.IX.1982, fl., G. Hatschbach 45454 (MBM). Pinhão, Rio Reserva, salto da Fazenda Reserva, 24.II.1996, fl., G. Hatschbach et al. 645 (MBM). Ponta Grossa, estrada que liga BR 376 a Itaiaoca, $25^{\circ} 07^{\prime} 43,8^{\prime \prime}$ ' $, 50^{\circ} 01^{\prime} 57,6^{\prime \prime} \mathrm{W}$, 1016 m.a.m., 21.IX.2002, fl., M. Magenta \& J. Magenta 477, 478 (SPF). Porto Amazonas, Recanto dos Papagaios, Rodovia BR 277, 5.X.2001, fl. e fr., J.M. Silva \& O.S. Ribas 3485 (MBM).

Espécie encontrada em pequenas populações esparsas no Paraná; possui ramos flexíveis com folhas opostas longas, de 8-19 cm de comprimento e capítulos geralmente solitários. É freqüentemente confundida com Aldama tenuifolia (Gardner) E.E. Schill. \& Panero, mas possue raízes muito delgadas, com uma grande tuberosidade globosa 
na região terminal, indumento hirsuto com tricomas multisseriados sem bossas ou com bossas inconspícuas, e escamas do pápus de ápice eroso, enquanto $A$. tenuifolia apresenta raízes com tuberosidade fusiforme nas porções basal ou central, indumento estrigoso, com tricomas 3 -seriados de bossas conspícuas na célula central e escamas do pápus com ápice eroso fimbriado. A semelhança entre as duas espécies levou Robinson (1984) a comentar que Aspilia linearifolia Baker (na verdade, A. tenuifolia) seria evidentemente Viguiera aspilioides Baker. Assim como esta última, A. linearifolia está representada por um desenho do tipo, no herbário $\mathrm{K}$, com referência a um número de coletor (Sello 1053) que, de acordo com o trabalho de Herter \& Rambo (1953) teria sido coletado em Minas Gerais, onde a espécie semelhante encontrada é $A$. tenuifolia.

Não foi possível localizar o material-tipo de Viguiera aspilioides ou qualquer imagem desta espécie entre os hebários internacionais visitados. O holótipo (Sello 669) estava provavelmente depositado em Berlim e, nesse caso, foi destruído durante a $2^{\mathrm{a}}$ guerra mundial. Nos registros fotográficos do herbário do Field Museum consta erroneamente como fotografia de tipo a imagem de um espécime coletado por Sello sob o número 1095. O único material encontrado analisado por Baker (com sua caligrafia) é um desenho de uma coleção de Sello, no herbário K, proveniente da mesma localidade do tipo, mas sem número e sem indicação do material utilizado para sua confecção. $\mathrm{Na}$ ausência de outro material representativo examinado nos herbários europeus visitados ou consultados, o esboço foi considerado como neótipo, já que o holótipo está desaparecido.

Aldama bakeriana (S. F. Blake) E. E. Schill. \& Panero, Bot. J. Linn. 167: 322. 2011. Viguiera bakeriana S. F. Blake, Contr. Gray Herbarium n. ser. 54: 131. 1918. Rhysolepis bakeriana (S. F. Blake) H. Rob. \& A. J. Moore, Proc. Biol. Washington 117(7): 425. 2004. Tipo: BRAZIL. [MINAS GERAIS]: 'Environs de Rio de Janeiro et Ouro Preto, 188384', Glaziou 15007 [Minas Gerais, entre Barbacena \& Sitio, 15.XI.1884 (P)] (lectótipo aqui designado: $\mathrm{K}$ !; fotografia do lectótipo: K!, SPF!; isolectótipos: $\mathrm{P}$ !, frag. $\left.\mathrm{GH}, \mathrm{NY}^{*}\right)$.

Tridens varius Pohl ex Baker in Mart. \& Eichler, Fl. bras. 6(3): 225. 1884, nom. nud. pro syn. Aldama subdentata (S. F. Blake) E. E. Schill. \& Panero, Bot. J. Linn. 167: 325. 2011. Viguiera subdentata S. F. Blake, Contr. Gray Herb. 54: 131. 1918. Rhysolepis subdentata (S. F. Blake) H. Rob. \& A. J. Moore, 1.c.: 432. 2004. Tipo: BRÉSIL. PROVINCE DE MINAS GERAES: 1816 a 1821, A. St.-Hil. 1160 (holótipo: P!; fotografia do holótipo: GH!; isótipo: US*). syn. nov.

Material selecionado: BRASIL. BAHIA: Ilhéus, VIII.1894, fl., A. Silveira 205 (R). MINAS GERAIS: Alpinópolis, rodovia Alpinópolis - Carmo do Rio Claro, 3 km antes Alpinópolis, $\mathrm{km} 536,20^{\circ} 52^{\prime} 44^{\prime \prime} \mathrm{S}, 46^{\circ} 24^{\prime 2} 22^{\prime \prime} \mathrm{W}$, 907 m.a.m., 21.X.2001, fl. e fr., M. Magenta \& J. Magenta 291 (K, SPF). Congonhas, rodovia BR $383 \mathrm{~km}$ 8, entre a BR 040 e São João Del Rei, Serra da Moeda, 22.X.2002, fl. e fr., M. Magenta \& J. Magenta 492 (SPF). Esmeraldas, estrada que vai de Esmeraldas para Ribeirão das Neves, km 7, 20.X.2002, fl. e fr., M. Magenta \& $J$. Magenta 485 (SPF). Lagoa Dourada, rodovia BR 383 km 73, sentido Lagoa Dourada - São João Del Rei, $20^{\circ} 57^{\prime} 39,2^{\prime \prime S}, 44^{\circ} 07^{\prime} 10,2^{\prime \prime} \mathrm{W}, 1130$ m.a.m., 22.X.2002, fl. e fr., M. Magenta \& J. Magenta 494 (SPF). Lagoa Santa, XI.1915, fl. e fr., F.C. Hoehne 6480 (R). Lassance, Serra do Cabral, 9.XII.1919, fl., A. Lutz 1572 (R). Pedra do Indaiá, rodovia MG $050 \mathrm{~km} \mathrm{165}$, sentido Divinópolis

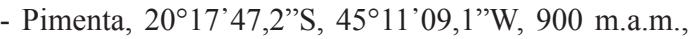
20.X.2002, fl. e fr., M. Magenta \& J. Magenta 484 (SPF). Santana do Riacho, Parque Nacional da Serra do Cipó, trilha para Cachoeira do Gavião, 19²0'35,3'S, $43^{\circ} 35^{\prime} 16,3^{\prime}$ 'W, 822 m.a.m., 21.X.2002, fl., M. Magenta \& J. Magenta 487 (SPF); São João del Rey, X.1969, fl. e fr., L. Krieger, Pe. 7412 (CESJ, RB, SPF). Sete Lagoas, CNPMS, Embrapa, 28.X.1982, fl., R.C.F. de Carvalho 92 (BHCB). Várzea da Palma, Fazenda Mãe D’Agua, 21.XI.1962, fr., A.P. Duarte 7424 (RB).

Espécie com folhas denteadas a serreadas na metade superior, que ocorre principalmente nas regiões noroeste, centro-oeste e sudoeste do estado de Minas Gerais, em cerrados íntegros ou degradados. Diferencia-se de Aldama discolor (Baker) E.E. Schill. \& Panero, por apresentar brácteas involucrais externas inteiramente foliáceas com uma nervura levemente destacada e ápice acuminado e pápus com aristas intramarginais eretas, sem carena ou com carena inconspícua; A. discolor, por sua vez, tem brácteas involucrais externas com base canaliculada, com $1-3$ nervuras muito salientes, foliáceas em $1 / 2$ superior e ápice agudo ou obtuso e pápus com aristas marginais recurvadas, robustas, com carena conspícua.

Blake (1918) descreveu Viguiera subdentata, diferenciando-a de $V$. bakeriana por apresentar brácteas involucrais em duas séries, enquanto a segunda teria invólucro com três a quatro séries de brácteas; a observação em campo mostrou que a distinção em duas espécies não procede, pois a variação no número de séries de brácteas pode ser 
observada numa mesma população. Blake (1918) cometeu um erro, ao relacionar $V$. bakeriana ao nome $V$. dissitifolia Baker (basiônimo Leighia dissitiolia); cujo tipo, ao ser examinado, mostrou corresponder a $V$. anchusifolia (DC.) Baker.

Somente o espécime depositado no herbário $\mathrm{K}$ possui identificação manuscrita por $\mathrm{S}$. F. Blake, com as informações citadas no protólogo da espécie. Interpreta-se isso como clara evidência de ser efetivamente o material usado pelo autor para a descrição e por isso sua escolha como lectótipo.

Aldama bracteata (Gardner) E. E. Schill. \& Panero, Bot. J. Linn. 167: 322. 2011. Viguiera bracteata Gardner, London J. Bot. 7: 404. 1848. Tipo: BRAZIL. GOYAZ: Dry upland campos, between Arrayas and San Domingos, V.1840, Gardner 4234 (lectótipo aqui designado: K! ex Herb. Hookerianum; fotografia do lectótipo: $\mathrm{K}$ !, SPF!; isolectótipos: BM!, $\mathrm{K}$ ! ex Herbarium Benthamianum, US* $2 x$, frag. $\mathrm{GH}$, fotografia de isolectótipo[G!]).

Aldama imbricata (Baker) E. E. Schill. \& Panero, Bot. J. Linn. 167: 325. 2011. Viguiera imbricata Baker in Mart. \& Eichler, Fl. bras. 6 (3): 220. 1884. Tipo: BRAZIL. Pohl 584 (holótipo: K!, isótipo: frag. $\mathrm{G}, \mathrm{W}^{*}$; fotografia de isolectótipo de B [destruído]: F!). syn. nov.

Aldama hilairei (S. F. Blake) E. E. Schill. \& Panero, Bot. J. Linn. 167: 323. 2011. Viguiera hilairei S. F. Blake, Contr. Gray Herbarium n. ser. 54: 153. 1918. Tipo: BRAZIL. MINAS GERAES: 1816-21, A. St.-Hil. 1208 [C1 415] (lectótipo aqui designado: $\mathrm{P}$ !; isolectótipo: $\mathrm{P}$ !). syn. nov.

Aldama quinqueremis (S. F. Blake) E. E. Schill. \& Panero, Bot. J. Linn. 167: 323. 2011. Viguiera quinqueremis S. F. Blake, Contr. Gray Herb. 54: 168. 1918. Tipo: BRAZIL. MINAS GERAIS: 1816 - 21, A. St.-Hil. 1218 [B1 1129 (P!)] (holótipo: P!; fotografia do holótipo: K! SPF!). syn. nov.

Material selecionado: BRASIL. DISTRITO FEDERAL: Brasília, próximo ao Jardim Botânico de Brasília, no Cond. Ecológico Vilage III, $15^{\circ} 52^{\prime} 02,2^{\prime \prime}$, 47²4'53,2”W, 4.XI.2001, fl., M. Magenta \& J. Magenta 312 (SPF). GOIÁS: Alto Paraíso de Goiás, Chapada dos Veadeiros, $1^{\circ} 01^{\prime} 47,3$ "S, 47 $31^{\circ}$ '47,2'W, 1506 m.a.m., 24.I.2002, fl. e fr., M. Magenta \& J. Magenta 378 (SPF). Caldas Novas, termas do Rio Quente, Reserva Ecológica do Roncador, 14.V.1980, fl. e fr., E.P. Heringer 17807 (HEPH, IBGE). Campo Alegre de Goiás, rodovia BR $050 \mathrm{~km} \mathrm{182,} \mathrm{estrada} \mathrm{Campo} \mathrm{Alegre} \mathrm{-} \mathrm{Cristalina,}$ $17^{\circ} 25^{\prime} 22,2^{\prime \prime}$ 'S, $47^{\circ} 47^{\prime} 44,1^{\prime \prime}$, 945 m.a.m., 20.I.2002, fl., M. Magenta \& J. Magenta 363 (SPF). Cristalina,
Rodovia BR $050 \mathrm{~km}$ 10, Sul de Cristalina, 16 48 '57,5”'S, $47^{\circ} 40^{\prime} 8,7^{\prime}$ 'W, 1225 m.a.m., 16.XII.2001, fl., M. Magenta et al. 333 (SPF). Pirenópolis, alto da Serra de Pireneus, na base dos 3 picos, 8.XI.1970 fl., J.A. Rizzo \& A. Barbosa 5711 (UFG). MATO GROSSO DO SUL: Corumbá, 10.IV.1967, fl., E.P. Heringer 11407 (RB). MINAS

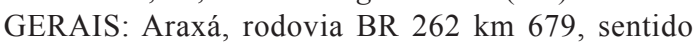
Araxá - Belo Horizonte, 19³2'57,7'S, 46 50'57,4”W, 936 m.a.m., 18.IV.2003, fl. e fr., M. Magenta \& J. Magenta 641 (SPF). Coromandel, Chapadão do Pau da Terra, Rodovia MG-040 km 292, entre Guarda-Mor e Coromandel, $18^{\circ} 07^{\prime} 21,7^{\prime \prime} \mathrm{S}, 47^{\circ} 05^{\prime} 01,7^{\prime \prime} \mathrm{W}, 930$ m.a.m., 22.IV.2003, fl., M. Magenta \& J. Magenta 667 (SPF).

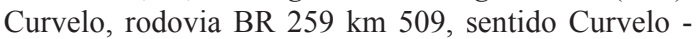
Gouveia, $18^{\circ} 35^{\prime} 50,5^{\prime}$ 'S, 46 $6^{\circ} 57^{\prime} 12,9^{\prime \prime} \mathrm{W}, 1116$ m.a.m., 18.IV.2003, fl. e fr., M. Magenta \& J. Magenta 644 (K, SPF). Jaboticatubas, Serra do Cipó, Chapéu de Sol, $19^{\circ} 40^{\prime}$ S, $43^{\circ} 57^{\prime} \mathrm{W}, 1000$ m.a.m., 29.IV.1952, fl. e fr., L.B. Smith 7009 (R, US). Montes Claros, rodovia BR

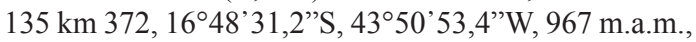
20.IV.2003, fl. e fr., M. Magenta \& J. Magenta 658 (SPF). Paracatu, rodovia BR 040, Paracatu - Cristalina, $68 \mathrm{~km}$ de Paracatu, 21.IV.1998, fl. e fr., F.B. Costa et al. 67 (SPF, SPFR). Município indefinido: 1816-21, A. St.-Hil. 1216 [B1 1125 (P!)] (parátipo de V. quinqueremis: P!).

Encontrada em Goiás, na Serra da Gibóia e em Alto Paraíso de Goiás, na Chapada dos Veadeiros, em altitudes acima de 1300 m.a.m. e com aparência mais robusta em Minas Gerais, na Cadeia do Espinhaço, nas Serras do Cipó e do Cabral, e a oeste, na Serra da Canastra (nesta última apresentando um fenótipo peculiar, com folhas e sinflorescências muito adensadas, descrito por Blake em Viguiera hilairei). A espécie pode ser reconhecida pelas folhas verdeclaras e pelas brácteas involucrais desiguais em 4-5(-6) séries. A variação no número de séries de brácteas involucrais e na morfologia das folhas (lâmina lanceolada a linear, base atenuada a cuneada, ápice agudo a acuminado, inteira ou esparsamente denticulada ou raramente crenada) levou Baker (1884) a descrever V. imbricata, e Blake (1918) a apresentar como espécies novas $V$. hilairei e $V$. quinqueremis. O formato dessas brácteas também varia, possuindo ápice agudo quando os capítulos estão imaturos e ápice longamente acuminado na maturidade. $\mathrm{O}$ exame detalhado das estruturas reprodutivas de todas essas plantas mostrou que se tratam apenas de variabilidade fenotípica.

A escolha do lectótipo baseou-se no fato de que apenas este material apresenta etiquetas de campo e da exsicata anotadas por Gardner, e cujas informações estão citadas no protólogo. 
Aldama discolor (Baker) E. E. Schill. \& Panero, Bot. J. Linn. 167: 322. 2011. Viguiera discolor Baker in Mart. \& Eichler, Fl. bras. 6(3): 228. 1884. Tipo: [BRASIL]. MINAS GERAES: In campis ad Caldas, [18/9/964] Regnel III.771 (lectótipo aqui designado: S! [S 04-923]; fotografia do lectótipo: $\mathrm{K}$ !, SPF!; isolectótipos: BR! 2x, GH - esboço, ex. herb. Stockholm, R!, RB!, S! [R 6476 e S 04-922], US*; fotografia de isolectótipo de B [destruído]: F!). Aldama obtusifolia (Baker) E. E. Schill. \& Panero, Bot. J. Linn. 167: 324. 2011. Viguiera obtusifolia Baker in Mart. \& Eichler, Fl. bras. 6 (3): 226. 1884. Rhysolepis obtusifolia (DC.) H. Rob. \& A. J. Moore, Proc. Biol. Washington 117(7): 430. 2004. Tipo: BRASIL. Pohl 581 (lectótipo aqui designado: $\mathrm{K}$ !, fotografia do lectótipo: K, SPF; isolectótipos: BR!, C, F*, frag. GH). syn. nov.

Material selecionado: BRASIL. GOIÁS: Campo Alegre de Goiás, rodovia BR 050, sentido Campo Alegre -

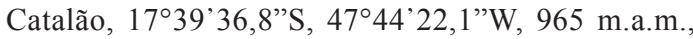
5.XI.2001, fl. e fr., M. Magenta \& J. Magenta 315 (SPF). MINAS GERAIS: Araxá, rodovia BR $428 \mathrm{~km}$ 41,5, Araxá

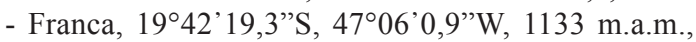
6.XI.2001, fl. e fr., M. Magenta \& J. Magenta 322 (SPF). Ituiutaba, rodovia BR $365 \mathrm{~km} \mathrm{433}$, sentido Ituiutaba Uberlândia, 1853'33,7'S, 48 13'11,1"W, 690 m.a.m., 14.XI.2004 fl., M. Magenta \& J. Magenta 723 (SPF). Paracatu, 14.X.1965, fl., A.P. Duarte 9274-A (RB). Poços de Caldas, próximo à estação ferroviária, junto ao Morro das Camisinhas, 2150'20"'S, 46³3'53”W, 9.III.1983, fl. e fr., H.F. Leitão Filho et al. 2049 (UEC). São Roque de Minas, Serra da Canastra, estrada para o Retiro das Pedras, XII.1994, fl., R. Romero et al. 1550 (HUFU). São Sebastião do Paraíso, estrada Itamogi - São Sebastião

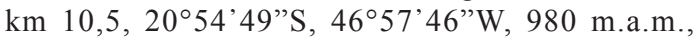
20.X.2001, fl. e fr., M. Magenta \& J. Magenta 279 (SPF).

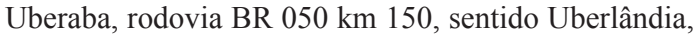
$19^{\circ} 39^{\prime} 50,5^{\prime \prime}$, $48^{\circ} 00^{\prime} 2,2^{\prime \prime}$ W, 700 m.a.m., 2.XI.2001, fl. e fr., M. Magenta \& J. Magenta 300 (K, SPF, SPFR). SÃO PAULO: Altinópolis, Morro do Forno, 19.XI.1992, fl., $W$. Marcondes-Ferreira et al. 507 (SPFR). Cristais Paulista, Estrada Franca - Pedregulho 1,5 km da entrada Cristais, $20^{\circ} 23^{\prime} 24,8^{\prime \prime}$ S, 4746’01,8”'W, 1025 m.a.m., 1.XI.2001, fl. e fr., M. Magenta \& J. Magenta 294 (HUFU, K, SPF, TEX). Ilha Solteira, município de Selviria, 6.IX.1984, fl. e fr., F.R. Martins et al. 16316 (UEC). Itirapina, 13.XI.1984, fl. e fr., S.N. Pagano 582 (HRCB, SPF); Mogi Guaçu, Fazenda Campininha, III.1996, fl., F.B. Costa 6 (SPFR).

A espécie é encontrada no nordeste e oeste de Minas Gerais e parte do sudeste de São Paulo, ou mais raramente no sul de Goiás, em cerrados típicos, campos sujos, campos rupestres e cerrados degradados. O epíteto específico está relacionado à cor esbranquiçada da face abaxial foliar de grande parte dos espécimes, conferida pelo indumento alvo-tomentoso. No entanto, quando o indumento é híspido, é confundida com Aldama bakeriana (S.F. Blake) E. E. Schill. \& Panero, da qual se diferencia principalmente por características do invólucro, das páleas e do pápus (ver comentários de $A$. bakeriana). Possui hábito e cipselas muito semelhantes aos de A. squalida (S. Moore) E. E. Schill. \& Panero, mas diferencia-se pelo caule subterrâneo com espessamento leve, pelas folhas com base levemente atenuada a cordada e face abaxial tomentosa ou híspida, pelas brácteas involucrais com face abaxial vilosa, estrigosa ou setosa e pelas anteras terminando na base do colar da antera, enquanto a segunda apresenta caule subterrâneo fortemente espessado, folhas com base obtusa a cuneada e glabras, esparsamente estrigosas ou estrigosas, hirsutas ou setosas, brácteas involucrais com face abaxial esparsamente estrigilosa a estrigilosa e anteras terminando acima da base do colar da antera. Baker (1884) descreveu Viguiera obsusifolia, difenrenciando-a por apresentar folhas de lâmina largamente oblonga, mas seu espécime-tipo apresenta folhas com lâmina arredondada, variação observada diversas vezes numa mesma população de $A$. discolor durante os trabalhos de campo, justificando a sinonimização.

No herbário $\mathrm{S}$ há também um material catalogado como Regnel III. 771 a (S!, GH - esboço ex herb. Stockholm), com a localização do lectótipo (“Territ. Caldense, prov. Minarum", 1864).

A lectotipificação seguiu dois critérios: os dados constantes no protólogo da descrição da espécie e o herbário onde o material se encontra depositado (Baker descreveu espécies principalmente a partir de exemplares dos herbários $\mathrm{BM}, \mathrm{BR}$ e K; o único material tipo foi encontrado no herbário BR). A despeito de haver materiais coletados em dois locais diferentes, no protólogo Baker citou a cidade de Caldas.

Aldama grandiflora (Gardner) E. E. Schill. \& Panero, Bot. J. Linn. 167: 323. 2011. Leighia grandiflora Gardner in Field \& Gardn., Sert. Pl. Viguiera grandiflora (Gardner) Gardner, London J. Bot. 7: 404. 1848. Viguiera grandiflora f. typica S. F. Blake, Contr. Gray Herb. 54: 127. 1918. Tipo: [BRAZIL. GOYAZ]: Dry Hills near Mission of Duro, X.1839, Gardner 3288 (holótipo: OXF, isótipos: BM!, frag. GH, K! - 2x, NY*, P!, RB!; fotografia de isótipo de B [destruído]: F!). 54-55. 1844. 
Viguiera macrantha Glaz., Bull. Soc. Bot. Fr. 57. Mém. 3: 413, nom. nud. pro syn.

Viguiera grandiflora f. latifolia (Baker) S. F. Blake, Contr. Gray Herb. 54: 127. 1918. Viguiera grandiflora var. latifolia Baker in Mart. \& Eichler, Fl. bras. 6(3): 224. 1884. Tipo: BRAZIL. GOYAZ: Dry wooded campos, Missione of Duro, X.1839, Gardner 3288 (bis) (lectótipo aqui designado: K!, fotografia do lectótipo: K!, SPF!). syn. nov. Aldama macropoda (S. F. Blake) E. E. Schill. \& Panero, Bot. J. Linn. 167: 324. 2011. Viguiera macropoda S. F. Blake, Contr. Gray Herb. 54: 128. 1918. Tipo: BRÉSIL. PROVINCE DE MINAS GERAIS: A. St.-Hil. 1157 (holótipo: P!; fotografia do holótipo: K!, SPF!). syn. nov.

Material selecionado: BRASIL. BAHIA: Rio de

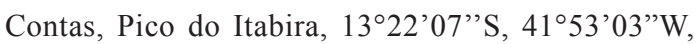
1800 m.a.m., 15.XI.1996, fl. e fr., R.M. Harley et al. 4296 (ALCB, HRB, HUEFS, SPF). DISTRITO FEDERAL: Sobradinho, rodovia DF $01 \mathrm{~km} \mathrm{9,} \mathrm{sentido}$ Paranoá - Sobradinho, $15^{\circ} 43^{\prime} 40,4^{\prime \prime} \mathrm{S}, 47^{\circ} 47^{\prime} 21,9^{\prime \prime} \mathrm{W}$, 1194 m.a.m., 23.I.2002, fl. e fr., M. Magenta \& $J$. Magenta 371 (SPF). GOIÁS: Abadiânia, rodovia BR $360 \mathrm{~km} \mathrm{17}$, sentido Alexânia - Abadiânia, 15⒌'18'S, $48^{\circ} 10^{\prime} 28^{\prime \prime}$, 4.XI.2001, fl. e fr., M. Magenta \& $J$. Magenta 310 (K, SPF, SPFR). Alto Paraíso de Goiás, próximo ao povoado de São Jorge, $14^{\circ} 10^{\prime} 59^{\prime \prime}$, 47049'18”'W, 1060 m.a.m., 2.VIII.2002, fl. e fr., $M$. Magenta et al. 271 (K, SPF, TEX). Niquelândia, Fazenda Engenho, ca. $11 \mathrm{~km}$ de Niquelândia em direção a Dois Irmãos, $14^{\circ} 34^{\prime} 41^{\prime \prime}$ S, 48²3’43”W, 3.X.1997, fl., M.L. Fonseca et al. 1629 (HEPH). Piracanjuba, Rochedo, 25.IX.1975, fl., G. Hatschbach 37174 (LP, MBM). Planaltina, $14 \mathrm{~km}$ de Planaltina, $5 \mathrm{~km}$ da Lagoa Formosa, $600 \mathrm{~m}$ do Córrego Maranhão, 1150 m.a.m., 9.X.1992, fl., J. Fontella \& J.E. Paul 2855 (RB). MATO GROSSO: Alto Araguaia, $74 \mathrm{~km}$ Alto Araquaia para Goiânia, 930 m.a.m., 30.IX.1963, fl., J.M. Pires 56977 (UB). São Vicente, rodovia BR 364, Serra de São Vicente, ca. $60 \mathrm{~km}$ de Cuiabá, 26.X.1981, fl., F. Sonoda \& N. Menezes 20 (UFMT). MATO GROSSO DO SUL: Alcinópolis, Fazenda Água Limpa, $18^{\circ} 13^{\prime} \mathrm{S}$, 535' 'W, 450 m.a.m., 28.X.1999, fl. e fr., A. Pott \& V.J. Pott 8137 (CPAP, SPF). Bandeirantes, rodovia BR 163, São Pedro, 6.XI.1996, f1., G. Hatschbach et al. 65352 (MBM). MINAS GERAIS: Babilônia, Babilônia - São João Batista da Glória sentido Delfinópolis, X.1997, f1., F.B. Costa 35 (SPFR). Buritizeiro, ponto 279, RADAMBRASIL, $17^{\circ} 15^{\prime} \mathrm{S}, 45^{\circ} 12^{\prime} \mathrm{W}, 750$ m.a.m., 17.XI.1981, fl. e fr., O.A. Salgado 239 (HPR, HRB, HUEFS). São Roque de Minas, Serra da Canastra, estrada para a Serra da Chapada, 14.X.1997, fl., $R$. Romero et al. 4603 (HUFU, UEC). Unaí, Fazenda São Miguel, Grupo Votarantim, próximo Ribeirão Bebedouro, $15^{\circ} 55^{\prime} \mathrm{S}, 46^{\circ} 40^{\prime} \mathrm{W}, 950$ m.a.m., 8.XI.1993, fl. e fr., M. Silva et al. 1694 (HEPH, IBGE, US).
TOCANTINS: Arraias, 5-10 km da rodovia para Paranã, Tocantins, 500 m.a.m., 10.XI.1991, fl., G. Hatschbach et al. 56012 (BR, CTES, HUEFS, MBM); Dianópolis, X.1839, fl. e fr., G. Gardner 3288 (BM, K, RB).

Aldama grandiflora ocorre no Distrito Federal, noroeste e nordeste de Goiás, sul e sudoeste de Mato Grosso, norte de Mato Grosso do Sul, noroeste de Minas Gerais e sul da Bahia, em cerrados típicos e campos. Caracteriza-se pelos capítulos grandes, com 5-10 cm de diâmetro, e pelas brácteas involucrais levemente apressas na floração, em 2-3 séries. Seus representantes são tolerantes a diferentes intensidades luminosas, condições refletidas na variação da forma e da cor da lâmina foliar: indivíduos habitando ambientes abertos ensolarados geralmente apresentam um maior número de folhas orbiculares e mais claras do que os de locais sombreados, nos quais as folhas possuem lâminas elípticas a largamente elípticas, oblongas a largamente oblongas, obovais, largamente obovais ou lanceoladas. A observação em campo demonstrou que as diferenças de forma foliar, característica utilizada por Blake (1918) para separar a espécie em duas formas distintas, não procedem; a forma das folhas varia numa mesma população e até num único indivíduo (ex.: R.M. Harley 4296, A.P. Duarte 10313).

Alguns indivíduos desta espécie podem ser muito semelhantes a certos espécimes de Aldama squalida (S. Moore) E. E. Schill. \& Panero, sendo às vezes impossível diferenciá-las em estado vegetativo. A distinção se faz com facilidade por meio das brácteas involucrais sempre linear-lanceoladas com face abaxial estrigosa a densamente estrigosa em $A$. grandiflora, e também de seu fruto geralmente longo (6,5-8,5 $\mathrm{mm}$ de alt.) e estreito, e pápus com aristas livres de ápice longamente acuminado, enquanto $A$. squalida possui brácteas involucrais elípticolanceoladas a oval-lanceoladas ou raramente oblongo-lanceoladas, com face abaxial glabra a esparsamente estrigilosa e cipselas menores (5-6,5 mm de alt.) e mais largas, e pápus com aristas unidas às escamas laterais.

$\mathrm{Na}$ descrição da espécie, Baker citou apenas o número 3288 , em cuja coleção incluiu exemplares da variedade típica e da variedade latifolia. No entanto Baker anotou 3288 (bis) com o nome Aldama grandiflora var. latifolia; portanto este foi aqui selecionado lectótipo deste último. 
Aldama kunthiana (Gardner) E. E. Schill. \& Panero, Bot. J. Linn. 167: 323. 2011. Viguiera kunthiana Gardner, London J. Bot. 7: 399. 1848. Rhysolepis kunthiana (Gardner) H. Rob. \& A. J. Moore, Proc. Biol. Washington 117(7): 427. 2004. Tipo: BRAZIL. GOYAZ: Dry upland campos, Mission of Duro, X.1839, Gardner 3285 (lectótipo aqui designado: K! ex Herb. Hookerianum; fotografia do lectótipo: $\mathrm{K}$ !, SPF!; isolectótipos: $\mathrm{BM}$ !, K! ex Herb. Benthamianum, NY*, frag. e esboço GH).

Ichthyothere dubia Glaz., Bull. Soc. Bot. France 57. Mém. 3(d). 409. 1910, nom. nud. pro syn.

Aldama angustissima (S. F. Blake) E. E. Schill. \& Panero, Bot. J. Linn. 167: 322. 2011. Viguiera angustissima S. F. Blake, Contr. Gray Herbarium 54: 118. 1918. Tipo: BRAZIL. GOYAZ: Campo between Rajadinha e Paranauna, Glaziou 21561 (lectótipo aqui designado: K!; fotografia do lectótipo: F!, K!, SPF!; isolectótipos: BR!, G, frag. GH, US*). syn. nov.

Material selecionado: BRASIL. DISTRITO FEDERAL: Brasília, Reserva Ecológica do IBGE, brejo próximo ao Córrego Taquara, $15^{\circ} 55^{\prime} 55^{\prime}$ 'S, $47^{\circ} 83^{\prime} 81^{\prime \prime} \mathrm{W}, 1015$ m.a.m., 20.IX.1999, fl. e fr., M.L. Fonseca \& D. Alvarenga 2114 (HEPH, IBGE, UEC). GOIÁS: Alto Paraíso de Goiás, estrada para Colinas do Sul, ca. $35 \mathrm{~km}$ de Alto Paraíso de Goiás, próximo ao povoado de São Jorge, $14^{\circ} 10^{\prime} 59^{\prime}$ 'S, 4749’18”W, 1060 m.a.m., 2.VIII.2002, fl. e fr., $M$. Magenta et al. 272 (SPF); Caiapônia, Serra do Caiapó, ca. $50 \mathrm{~km}$ de Caiaponia para Jataí, $17^{\circ} 12^{\prime} \mathrm{S}, 51^{\circ} 47^{\prime} \mathrm{W}, 900$ m.a.m., 25.X.1964, fl., H.S. Irwin \& T.R. Soderstrom 7239 (UEC); Caldas Novas, 20.XII.1951, fl., A. Macedo 3533 (RB); Campo Alegre de Goiás, rodovia BR 050, sentido Campo Alegre - Catalão, $17^{\circ} 58^{\prime} 39,8^{\prime \prime} \mathrm{S}, 47^{\circ} 47^{\prime} 45,3^{\prime \prime} \mathrm{W}$, 865 m.a.m., 5.XI.2001, fl. e fr., M. Magenta \& J. Magenta 316 (SPF); Minaçu, estrada de terra Minaçu, Serra da Mesa, $2 \mathrm{~km}$ da entrada $\mathrm{N}$ do canteiro de obras da UHE, $13^{\circ} 51^{\prime} \mathrm{S}, 48^{\circ} 15^{\prime} \mathrm{W}, 550$ m.a.m., 20.XI.1991, fl., B.M.T. Walter et al. 781 (CEN, K, SPF); Município indefinido: Goyaz, Pohl (como Tridens hispidus, W*). MINAS GERAIS: Araxá, rodovia BR $428 \mathrm{~km} \mathrm{27}$, sentido Araxá - Franca, 1942'47'S, 46'59'26,4”W, 6.XI.2001, fl. e fr., M. Magenta \& J. Magenta 321 (SPF). Babilônia, Babilônia - São João Batista da Glória, X.1997, F.B. Costa 32 (SPFR). Santa Bárbara, estrada Rio Acima, Fazenda Gandarela, 14 km Rio Acima, 31.X.1966, fl. e fr., A.P. Duarte 958 (M). Unaí, Fazenda São Miguel, Grupo Votarantim, próximo ao Ribeirão Bebedouro, $15^{\circ} 55^{\prime}$ S, 46 $40^{\prime}$ W, 8.XI.1993, M.A. Silva et al. 1688, 1691 (HEPH). TOCANTINS: Dianópolis, Mission of Duro, X.1841, fl. e fr., G. Gardner 3285 (BM, K, P). Natividade, Serra de Natividade, XII.1839, G. Gardner 3284 (K, P). Palmeirópolis, Serra Dourada, 12.II.1991, fl., G. Hatschbach \& M. Hatschbach 56100 (BR); Ponte Alta do Tocantins, Macedo, in midle of Tocantins
Ultramatic Complex, $1.8 \mathrm{~km}$ along $\mathrm{S}$ Ridge road towards Ponte Alta, 22.VI.1990, fl, R.R. Brooks \& R.D. Reeves TMEX $652(\mathrm{~K})$.

Ocorre no norte, noroeste e na porção central de Goiás, no noroeste e sudoeste de Minas Gerais e no Distrito Federal, em campos, brejos, borda de mata e de córregos. Possui ramos aéreos flexíveis e sistema subterrâneo geralmente espessado, brácteas involucrais levemente apressas na floração, em 2-3 séries, e cipselas obovóides ciliadas.

A espécie se assemelha aldama tenuifolia (Gardn.) E.E. Schill. \& Panero, e A. aspilioides (Baker) E.E. Schill. \& Panero, das quais se diferencia por apresentar brácteas involucrais menores, com até $11 \mathrm{~mm}$ compr., geralmente ovaloblongas com ápice agudo, enquanto as outras possuem brácteas que alcançam mais de $17 \mathrm{~mm}$ compr. e são lanceoladas ou elíptico-lanceoladas com ápice geralmente acuminado. Pode ainda ser distinguida de $A$. tenuifolia (receptáculo levemente convexo) pelo receptáculo fortemente convexo a levemente cônico.

Blake (1918) descreveu Viguiera angustissima, diferenciando-a de $V$. kunthiana por possuir folhas mais estreitas, canescentes e com uma só nervura. O trabalho de campo, aliado à observação dos materiais-tipo, demonstrou que o indumento e a largura da lâmina foliar são variáveis e, quando esta é estreita, apenas uma nervura é visível com facilidade.

Para a escolha do lectótipo de Viguiera kunthiana, foi selecionado o espécime que contém a etiqueta de identificação manuscrita por Gardner, proveniente do Herbário Hookerianum em Kew. Como lectótipo de $V$. angustissima, escolheu-se a exsicata do herbário K que contém uma informação manuscrita por Baker, relatando a doação de capítulos e folhas da mesma para Blake.

Aldama linearifolia (Chodat) E.E. Schill. \& Panero, Bot. J. Linn. 167: 324. 2011. Viguiera linearifolia Chodat, Bull. Herb. Boissier ser. 2 (2): 392. 1902. Rhysolepis linearifolia (Chodat) H. Rob. \& A.J. Moore, Proc. Biol. Washington 117(7): 429. 2004. Tipo: PARAGUAY: In campo pr. Ipê-hú, X.1998-1900 Hassler 4959 [in autoplanities et decliviis Sierra de Maracayú (K!)] (holótipo: G*; fotografia do holótipo: F!, K!, SPF!; isótipos: BM!, $\mathrm{G}^{*}, \mathrm{GH}^{*}, \mathrm{~K}$ !, P!, S!, W*).

Aldama rojasii (S. F. Blake) E. E. Schill. \& Panero, Bot. J. Linn. 167: 325. 2011. Viguiera rojasii S.F. Blake. Contr. Gray Herb. 54: 179. 1918. 
Tipo: PARAGUAI. [AMAMBAY]: Plateau and declivities of the Sierra de Amambay, IV.1907-08, Rojas 10367 (holótipo: BM!; isótipo: P!; frag. e fotografía do holótipo: GH). syn. nov.

Material selecionado: BRASIL. MATO GROSSO DO SUL: Ponta Porã, estrada Ponta Porã - Vista Alegre a $3,5 \mathrm{~km}$ trevo para João Antonio, na ferrovia, $22^{\circ} 18^{\prime} 32,6$ "S, 55 41 '58,1”'W, 691 m.a.m., 21.XI.2003, fl., M. Magenta \& J. Magenta 690 (SPF). PARAGUAI: Canindeyú, 18.XI.1996, fl., B. Jiménez 1714 (BM); Pedro Juan Cabalero, Fazenda El Buracon, $30 \mathrm{~km}$ de Pedro Juan Cabalero, 15.XII.1983, fl. e fr., G. Hatschbach \& R. Callejas 47271 (MBM). San Pedro, Yagareté

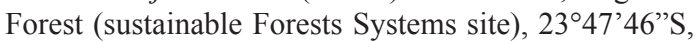
$56^{\circ} 12^{\prime} 41^{\prime \prime} \mathrm{W}$; 27.V.1998, fl. e fr., E.M. Zardini \& S.Zavala $46820(\mathrm{~K})$.

Espécie caracterizada pelo indumento alvolanoso na face abaxial das folhas lineares e nas flores tubulosas dos capítulos jovens, descrita com base em material do Paraguai; referida pela primeira vez para o Brasil por Magenta (2006), para a região de Ponta Porã, no Mato Grosso do Sul, em área pedregosa.

Foi confundida por Baker (1884) e Blake (1918) com Aldama filifolia (Sch. Bip. ex Baker) E. E. Schill. \& Panero, da qual difere pelo indumento lanoso alvo na face abaxial das folhas, e recobrindo as flores do disco jovens e páleas, além de pápus com aristas de base muito alargada e cerca de dois pares de escamas; a segunda não apresenta indumento lanoso e possui pápus com aristas estreitamente triangulares e cerca de quatro pares de escamas.

Aldama macrorhiza (Baker) E.E. Schill. \& Panero, Bot. J. Linn. 167: 324. 2011. Viguiera macrorhiza Baker in Mart., Fl. bras. 6(3): 225. 1884. Rhysolepis macrorhiza (Baker) H. Rob. \& A. J. Moore, Proc. Biol. Washington 117(7): 429. 2004. Tipo: [PARAGUAI. CAAGUAZÚ]: Habitat in Paraguay in Campos de Caaguazú, 16.XI.1874, Balansa 848 (lectótipo aqui designado: K!; fotografia do lectótipo: K!, SPF!; isolectótipos: G, $\mathrm{NY}^{*}, \mathrm{P}$ !; fotografia de isolectótipo: F!).

Viguiera hassleriana Chodat, Bull. Herb. Boissier ser. 2(3): 274. 1903. Viguiera macrorhiza f. hassleriana (Chodat) Hassl., Repert. Spec. Nov. Regni Veg. 14: 269. 1916. Tipo: PARAGUAY. In regions fluminis Tapiraguay, campo, VIII.190102, Hassler 4306 (lectótipo aqui designado: G*; fotografia do lectótipo de G: F; isolectótipos: BM! - 2x, P!; fotografia dos isolectótipos: $\mathrm{K}, \mathrm{SPF}$ !).

Material examinado: BRASIL. MATO GROSSO DO SUL: Salobra, XI.1941, fl., N. Santos (R 36962). Três Lagoas, Retiro das Telhas, $12^{\circ} 30^{\prime} \mathrm{S}, 40^{\circ} 29^{\prime} \mathrm{W}$,
22.X.1964, fr., J.C. Gomes 2397 (SP). MINAS GERAIS: Brasilândia, Fazenda Brejão, Mannesmann Florestal, 30.XI.1999, fl. e fr., A.A. Azevedo 176 (BHCB); Joaquim Felício, Serra do Cabral, estrada para torre de TV, $17^{\circ} 45^{\prime}$ S, $44^{\circ} 11^{\prime} \mathrm{W}, 6 . X \mathrm{XI} 1987$, fl., M.C. Assis et al. 11657 (SPF, US). Paracatu, Córrego Rico, 24.X.1978, fl., G. Hatschbach \& A. Kasper 41675 (MBM, UEC). PARANÁ: Taquarituba, Palmeiras, Rio dos Papagaios, 14.X.1966, fl., J.Lindeman \& H. Haas 3672 (MBM). SÃO PAULO: Águas de Santa Bárbara, Estação Ecológica de Santa Bárbara, 9.X.1990, fl., J.A.A. Meira Neto et al. 669 (UEC). Agudos, ca. $4 \mathrm{~km}$ da cidade e mais próximo do Posto Chapadão, 11.VI.1976, fl., H.F. Leitão Filho et al. 2149 (BM, UEC). Angatuba, Instituto Florestal de São Paulo, 23⒉ $27^{\prime} \mathrm{S}, 48^{\circ} 25^{\prime} \mathrm{W}, 19 . \mathrm{XI} .1983$, fl., J.A. Ratter \& G.C.G. Argent 4912 (UEC). Botucatu, rodovia São Manuel - Piracicaba, a $18 \mathrm{~N}$ de Botucatu e $14 \mathrm{~km}$ de São Manuel, $22^{\circ} 45^{\prime}$ S, $48^{\circ} 25^{\prime}$ W, 550 m.a.m., 31.VIII.1972, I.S. Gottsberger 24-31872 (BOTU, RB, UB). Mogi Guaçu, Reserva Biológica da Fazenda Campininha, estrada do pesqueiro a $4 \mathrm{~km}$ da entrada para viveiro, $22^{\circ} 12^{\prime} 13,1$ ' $\mathrm{S}$, 47¹1'18,6”W, 585 m.a.m., 1.X.2002, fl., M. Magenta \& J. Magenta 476 (SPF). Pirassununga, Cerrado de Emas, $22^{\circ} 02^{\prime}$ 'S, 47³7’W, 24.XI.1994, fr., S. Aragaki \& M. Batalha 174 (SP). PARAGUAI. [CAAGUAZU]: in Campos de caaguazuú: [16.XI.1874] Balanza 1139: K!). Município indefinido: Rio Carimbatay, campos, IX.190102, Hassler 4578: G*: BM!, frag. GH).

Espécie de ramos flexíveis com folhas largamente elípticas a obovais, capítulos solitários e cipselas com escamas unidas até próximo ao ápice eroso. Foi descrita originalmente como nativa do Paraguai e citada pela primeira vez para o Brasil por Magenta (2006), sendo encontrada nas regiões central e sudeste de São Paulo e nordeste e centro de Minas Gerais. Atualmente, Aldama macrorhiza parece estar restrita a áreas de preservação.

Os lectótipos foram selecionados de acordo com o exame de etiquetas anotadas pelos autores dos táxons e com o herbário de origem dos mesmos.

Aldama nudibasilaris (S. F. Blake) E. E. Schill. \& Panero, Bot. J. Linn. 167: 324. 2011. Viguiera nudibasilaris S. F. Blake, Contr. Gray Herbarium 54: 149. 1918. Rhysolepis nudibasilaris (S. F. Blake) H. Rob. \& A. J. Moore, Proc. Biol. Washington 117(7): 429. 2004. Tipo: BRASIL. MINAS GERAIS: Caldas, 27.III.1846, Widgren s.n. (holótipo: K! [K 1249/97]; fotografia do holótipo: K!, SPF; isótipos: BR!, M!, R!).

Aldama tuberculata (S. F. Blake) E. E. Schill. \& Panero, Bot. J. Linn. 167: 325. 2011. Viguiera tuberculata S. F. Blake, Contr. Gray Herbarium 54: 151. 1918. Rhysolepis tuberculata (S. F. Blake) H. Rob. \& A. J. Moore, Proc. Biol. Washington 117(7): 
432. 2004. Tipo: BRASIL. MINAS GERAIS: A.St.Hil. 1212 (holótipo: P!; fotografia do holótipo: K!, SPF!). syn. nov.

Material examinado: BRASIL. MINAS GERAIS: Barbacena, III.1941, fl., F. de Laueo (R 35073). Congonhas do Campo, Brésil, 8.VI.1884, fl. e fr., Glaziou 15080 (BR,P, K). 30.XII.1886, fl. e fr., Glaziou 16164 (P). Delfim Moreira, PCH Ninho de Águia, IV.2000, fl. e fr., L.V. Costa (BHCB 52511). Monte Verde, estrada Monte Verde - Camanducaia, a $1 \mathrm{~km}$ de Camanducaia, $23^{\circ} 06^{\prime} 53,2^{\prime \prime} \mathrm{S}, 46^{\circ} 01^{\prime} 16,7^{\prime}$ 'W, 851 m.a.m., 6.IV.2002, fl. e fr., M. Magenta \& J. Magenta 426 (K, SPF, SPFR); Poços de Caldas, Campo do Saco, 7.IV.1967, fl. e fr., A.R.A. Roppa 1027 (RB). Pouso Alegre, rodovia MG $390 \mathrm{~km} \mathrm{8}$, sentido Pouso Alegre - Borda da Mata, $22^{\circ} 15^{\prime} 49,4$ "S, 4559'31,5”W, 1493 m.a.m., 6.IV.2002, fl., M. Magenta \& J. Magenta 430 (SPF). São Lourenço, estrada São Lourenço - Carmo de Minas, II.1966, fl. e fr., A. Mattos Filho 441, 449 (EPAMIG, RB, SPF). SÃO PAULO: Campos de Jordão, Instituto Florestal, Região do Canhambora, trilha de equitação, 27.III.1985, fl. e fr., M.J. Robim \& J.P.M. Carvalho 256 (D, MBM, SPSF, UEC).

Espécie caracterizada pelas folhas levemente discolores, a lâmina medindo $5-10 \times 1,5-2 \mathrm{~cm}$, lanceolada, com base atenuada, decorrente e pelas cipselas com pápus dourado e escamas unidas até a metade. Foi coletada no nordeste do estado de São Paulo e sul de Minas Gerais em bordas de mata e campo sujo.

Aldama nudibasilaris apresenta morfologia similar a $A$. pilosa (que possui invólucro com brácteas em 3-4 séries, flores do disco 50-85, corola 4,5-5 $\mathrm{mm}$ alt., pápus com escamas de 0,8-1,1 mm alt. com ápice eroso-lacerado) mas diferencia-se pelo invólucro 2-seriado, pelas flores do disco geralmente maiores (corola com 4,5-7 mm alt.) e em maior número (100-120) e pelo pápus com escamas muito menores $(0,3-0,8 \mathrm{~mm}$ alt. $) \mathrm{de}$ ápice eroso. As características sutis utilizadas por Blake (1918) para estabelecer Viguiera tuberculata, relativas ao indumento das brácteas involucrais, ao tamanho das flores do disco e das aristas do pápus, mostraram-se variáveis em capítulos de um mesmo espécime (incluindo os materiais-tipo dos dois táxons, que também apresentam cipselas com margem espessada, uma característica única entre as espécies brasileiras); portanto, o nome foi considerado como sinônimo de $A$. nudibasilaris.

Aldama oblongifolia (Gardner) E.E. Schill. \& Panero, Bot. J. Linn. 167: 324. 2011. Viguiera oblongifolia Gardner, London J. Bot. 7: 402. 1848. Rhysolepis oblongifolia (Gardner) H. Rob. \& A. J. Moore, Proc. Biol. Washington 117(7): 430. 2004.
Tipo: BRAZIL. [GOYAZ]: Dry upland Campos, Mission of Duro, Province of Goyaz, X.1839, Gardner 3291 (lectótipo aqui designado: K! ex Herb. Hookerianum; fotografia do lectótipo: K!, SPF!; isolectótipos: BM!, G, frag. GH ,K! ex Herb. Trinity College, P!; fotografia do isolectótipo de G: F!). Aldama nervosa (Gardner) E. E. Schill. \& Panero, Bot. J. Linn. 167: 324. 2011. Viguiera nervosa Gardner, London J. Bot. 7: 403. 1848. Rhysolepis nervosa (Gardner) H. Rob. \& A. J. Moore, Proc. Biol. Washington 117(7): 429. 2004. Tipo: BRAZIL. GOYAZ: Bushy places in upland Campos near Villa de Natividade, Province of Goyaz, I.1840. [XII.1839 (BM!, K!)], Gardner 3290 (lectótipo aqui designado: K!; fotografia do lectótipo: K!, SPF; isolectótipos: $\mathrm{BM}$ !, $\mathrm{G}$, frag. $\mathrm{GH}, \mathrm{NY} * 2 \mathrm{x}$; fotografia do isolectótipo de G: F!). syn. nov.

Material selecionado: BRASIL. CEARÁ: Santana do Cariri, Tabuleiro, 9.III.1860, fl., F. Allemão 864 (R). GOIÁS: Caiapônia, rodovia BR 158 km 180, entre Jataí

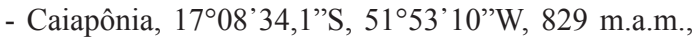
20.XII.2001, M. Magenta et al. 355 (SPF). Goiânia, XII.1936, A.C. Brade 15398 (RB). Iaciara, 15 km estrada Iaciara - Nova Rova, 5.II.1981, fl., R.M. King \& L.E. Bishop 8801 (K, UB). Juscelino Kubtschek, vale do Paranã, Rodovia JK 60, 6.II.1967, fl., A.P. Duarte 10333 (RB). Mossâmedes, Serra Dourada, 13.XII.1951, fl., A. Macedo 3464 (RB). Piranhas, rodovia BR $158 \mathrm{~km} 93$, sentido Bom Jardim - Piranhas, $16^{\circ} 23^{\prime} 24,6$ 'S, 51 49 49 '59,6”W, 370 m.a.m., 20.XII.2001, fl., M. Magenta et al. 349 (SPF). Uruaçu, estrada de terra da BR 153, passando pela Vila Água Branca, $14^{\circ} 23^{\prime} \mathrm{S}, 49^{\circ} 00^{\prime} \mathrm{W}, 400$ m.a.m., 7.II.1996, fl., B.M.T. Walter et al. 3084 (CEN). MARANHÃO: Balsas, estrada para Alto Parnaíba, a $6 \mathrm{~km}$ de Balsas, 7.XII.1980, fl., P. Martins e E. Nunes 9462, 9464 (RB). MATO GROSSO: [Água Boa], Projeto RADAMBRASIL, ponto $02 \mathrm{~A}$, Rio Xingu, $14^{\circ} 09^{\prime} \mathrm{S}, 51^{\circ} 59^{\prime} \mathrm{W}, 16 . \mathrm{XI} .1977$, fl. e fr., S.S. Silva \& R. Becker 6022 (HRB, RB). Barra do Garças, rodovia BR 158, sentido Barra do Garça - Nova

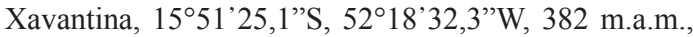
18.XII.2001, fl. e fr., M. Magenta et al. 340 (HUFU, K, SPF, SPSF, TEX). Luciara, rodovia BR 158 1-5 km W, $43 \mathrm{~km} \mathrm{~S}$ de Porto Alegre do Norte, $11^{\circ} 17^{\prime} \mathrm{S}, 51^{\circ} 45^{\prime} \mathrm{W}$, 17.X.1985, fl. e fr., W. Thomas et al. 4456 (K, SPF). Tapirapuã, III.1909, fl., F.C. Hoehne 1689 (R). MINAS GERAIS: Barrocão, $56 \mathrm{~km} \mathrm{NE}$ da estrada Barrocão - Porteirinha, 21.I.1981, fl., R.M. King \& L.E. Bishop 8585 (K, M, UB). TOCANTINS: Araguaína, ponto 17, RADAMBRASIL, $07^{\circ} 25^{\prime} \mathrm{S}, 48^{\circ} 22^{\prime} \mathrm{W}, 28$.XI.1983, fl., E. Mileski 407 (HRB). Cercadinho, rodovia Belém - Brasília, Fazenda Americana, próximo a Cercadinho, 9.I.1961, fl., L. Emygdio 1896 (R). Dianópolis, X.1939, fl. e fr., $G$. Gardner 3291 (BM, K, P).

Ocorre em cerrados abertos e campos, no sudoeste dos estados de Ceará, Goiás e Minas Gerais, sudeste e norte de Tocantins, sudoeste do 
Maranhão, sudeste e nordeste de Mato Grosso. A espécie é facilmente reconhecida pelos longos paracládios flexuosos e pelo invólucro com quatro séries de brácteas ovais a oval-lanceoladas que, na maioria das vezes, se mantêm apressas na floração. A variação na largura das folhas, principal caráter utilizado por Gardner para descrever Viguiera nervosa, é constantemente observada numa mesma população e até em ramos de um mesmo espécime de A. oblongifolia.

$\mathrm{O}$ material depositado no herbário $\mathrm{K}$, originário do herbário Hookerianum, foi selecionado como lectótipo de Viguiera oblongifolia por apresentar a etiqueta anotada por Gardner, com detalhes do protólogo da espécie. Na exsicata deste lectótipo está fixada ainda uma segunda etiqueta, com o número 3093, um erro provavelmente cometido pela pessoa responsável pela montagem do material, visto que este número corresponde, na verdade, ao tipo de Wedelia goyazensis Gardner, também depositado no herbário K. A seleção do lectótipo de $V$. nervosa foi efetuada com base nos mesmos critérios.

Aldama pilicaulis (S.F. Blake) E.E. Schill. \& Panero, Bot. J. Linn. 167: 324. 2011. Viguiera pilicaulis S. F. Blake, Contr. Gray Herbarium 54: 164. 1918. Viguiera robusta var. scaberrima Hassl., Repert. Nov. Regni. Veg. 14: 273. 1916. Rhisolepis pilicaulis (S.F. Blake) H. Rob. \&A.J. Moore, Proc. Biol. Soc. Wash. 117(3): 430. 2004. Tipo: PARAGUAI. [AMAMBAY]: Sierra de Amambay, II.1907-08, Rojas 10757 (lectótipo aqui designado: BM!; fotografia do lectótipo: K!, SPF!; isolectótipos: frag. $\mathrm{GH}, \mathrm{K}$ !; fotografia de isolectótipo de B [destruído]: F!).

Viguiera robusta Gardner var. confusa Hassl., Repert. Nov. Regni. Veg. 14: 274. 1916. Tipo: PARAGUAI. [AMAMBAY]: Sierra de Amambay. II.1907-08, Rojas (distr. Hassler) 10757a (G). syn. nov.

Material examinado: BRASIL. MATO GROSSO DO SUL: Guia Lopes da Laguna, rodovia BR $267 \mathrm{~km}$ 447, descida da chapada, 9.III.2003, fl., G. Hatschbach et al. 74393 (MBM, SPF).

A espécie foi descrita para o Paraguai e até o momento foi encontrado um único registro em território brasileiro, no Mato Grosso do Sul. Pode ser reconhecida pela presença de folhas alternas verde-claras com pecíolo viloso, capítulo com páleas de ápice obtuso a truncado e pápus com aristas unidas às escamas.

Foi citada pela primeira vez para o Brasil por Robinson \& Moore (2004) como Rhysolepis pilicaulis. Esses autores referiram oito a nove flores do raio para a espécie; já Blake (1918) ao descrever Viguiera pilicaulis contou 10 a 11 flores. Hassler (1916) também descreveu este táxon como uma variedade de Aldama robusta ( $V$. robusta var. confusa Hassl., caracterizando-o principalmente por ter caule densamente piloso na metade superior, folhas superiores alternas e sésseis, medianas opostas e sésseis e inferiores opostas e curtamente pecioladas cipselas viloso-seríceas com aristas duas vezes maiores que as escamas). Porém, $A$. pilicaulis se distingue de $A$. robusta por apresentar folhas verde-claras e cartáceas, brácteas involucrais sempre em três séries, pápus estramíneo com aristas unidas às escamas laterais; em $A$. robusta as folhas são discolores e coriáceas, o invólucro é, na grande maioria das vezes, formado por quatro a cinco séries de brácteas e o pápus é amarelado, com aristas livres. A designação do lectótipo se baseou na existência de uma etiqueta com a incrição "type Coll." manuscrita por Blake, no material depositado no herbário BM.

Aldama pilosa (Baker) E. E. Schill. \& Panero, Bot. J. Linn. 167: 324. 2011. Viguiera pilosa Baker in Martius, Fl. bras. 6(3): 223. 1884. Rhysolepis pilosa (Baker) H. Rob. \& A. J. Moore, Proc. Biol. Washington 117(7): 430. 2004. Tipo: [BRASIL]. Habitat in Brasilia, loco speciali ignoto, s.d., Sello 1028 ! (lectótipo aqui designado: K!; fotografia do lectótipo: K!, SPF!).

Viguiera malmei S. F. Blake, Contr. Gray Herbarium 54: 151. 1918. Tipo: BRAZIL. RIO GRANDE DO SUL: Rather moist pasture, near a wood, Rincão dos Valles, near Cruz Alta, 20 April 1893, Malme 794 (holótipo: BM!; fotografia do holótipo: K!, SPF!; isótipos: frag. e esboço $\mathrm{GH}, \mathrm{R}$ !, $\mathrm{S}^{*} 2 \mathrm{x}$, UPS). syn. nov.

Aldama salicifolia (Hassl.) E.E. Schill. \& Panero, Bot. J. Linn. 167: 325. 2011. Viguiera salicifolia Hassl., Repert. Spec. Nov. Regni. Veg. Beih 14: 274. 1916. Viguiera villaricensis S. F. Blake, Contr. Gray Herbarium 54: 152. 1918. Tipo: PARAGUAY. [GUAIRÁ]: Ad margines silvarum pr. Villarrica, flor et fruct. Mens. Jan., E. Hasller 8627 (lectótipo aqui designado: $G^{*}$; fotografia do lectótipo: $F$; isolectótipos: GH, K!, ex herb. Hassleriano, NY*). syn. nov.

Material selecionado: ARGENTINA. MISIONES: Apóstoles, de Azara a Concepión de La Sierra, $10 \mathrm{~km}$ de Azara, 1.V.1984, fl. e fr., F.O. Zuloaga et al. 1902 (RB, SI). Corrientes, Ituzaingó, 11.II.1971, fl., A. Krapovickas et al. 18075 (CTES). San Ignácio, 12.III.1946, fl., G.J. 
Sehwarz 2213 (R). BRASIL. PARANÁ: General Carneiro,

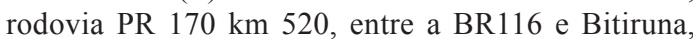
2811'17,7'S, 51³1'13,1”W, 895 m.a.m., 29.III.2002, fl. e fr., M. Magenta \& J. Magenta 420 (HUFU, K, SPF, SPFR). Turvo, Fazenda Rikli, 6.III.1991, fl. e fr., J.M. Silva \& S.D.P. Kricum 943 (MBM). RIO GRANDE DO SUL: Arroio dos Ratos, rodovia BR 290 km 154, sentido Arroio dos Ratos - Cachoeira do Sul, 3006'19,2"S, 51 ${ }^{\circ} 45^{\prime}$ 07,7'W, 82 m.a.m., 21.I.2003, fl., M. Magenta \& C. Mondin 500 (SPF). Esmeralda, Estação Ecológica de Esmeralda, 12.II.1979, fl. e fr., L.A. Arzivenco 566 (ICN). Ijuí, rodovia RS 342 km 129,4, sentido Ijuí - Cruz Alta, 28²9'34,7'S, 5349'43”'W, 411 m.a.m., 25.I.2003, fl. e fr., M. Magenta \& C. Mondin 529 (SPF). Nonoai, Sarandi - Nonoaí para Uruguai, III.1945, fl., B. Rambo s.n. (LP, PACA 28174). Santa Maria, Boca do Monte, III.1939, fl., J. Vidal (R 39461). Santana do Livramento, Cerro Paloma, 21.I.1986, fl., J.R. Mattos \& N.F. Mattos 28981 (HAS). Santo Antônio das Missões, estrada entre São Borja e Santo Antonio, 28²9'35,4’S, 55²3'37,9'W, 167 m.a.m., 24.I.2003, fl. e fr., M. Magenta \& C. Mondin 526 (SPF). São Francisco de Paula, Fazenda Englert para São Francisco de Paula, 8.II.1941, fl., B. Rambo (PACA 4446). Victor Graeff, rodovia BR $223 \mathrm{~km} 7,6$ sentido para Passo Fundo, 28³6'08,4’'S, 52³9'56,5’W, 497 m.a.m., 25.I.2003, fl. e fr., M. Magenta \& J. Magenta 534 (SPF). SANTA CATARINA: Calmon, arredores da cidade, beira da estrada, 14.IV.2004, fl. e fr., L.R. Lima \& J.M. Silva 359 (SPF). Lages, rodovia BR $116 \mathrm{~km} \mathrm{258,} \mathrm{sentido}$ Lages - Capão Alto, 2753'35,4’S, 50²5'23,4'”, 920 m.a.m., 27.III.2002, fl. e fr., M. Magenta \& J. Magenta 402 (SPF, SPFR); Santa Cecília, rodovia BR $116 \mathrm{~km}$ 131,5, Serra do Espigão, sentido São Cristovão do Sul Ponte Alta do Norte, 2654'19,4”'S, 50²6’22,8’'W, 1073 m.a.m., 27.III.2002, fl. e fr., M. Magenta \& J. Magenta 393 (K, SPF). São Joaquim, perto de Passo do Pires, no Rio Rondinha, IV.1965, fl., J.R. Mattos 12704 (HAS). São Miguel do Oeste, Rua das Flores, 1.III.1964, fl., $A$. Castellanos 24757 (RB).

Espécie com ramos aéreos setosos a pilosos, folhas de lâmina lanceolada a oval-lanceolada ou raramente oblonga e inteira a esparsamente serreada, é comum na Formação Serra Geral (White 1908), nos estados de Paraná, Santa Catarina e Rio Grande do Sul e também na Argentina e no Paraguai, em bordas de mata, mata ciliar, cerrados, beira de estrada e capoeiras. De acordo com as observações de campo, aparentemente, forma híbridos $\operatorname{com} A$. anchusifolia. Em estado vegetativo é parecida com Aldama nudibasilaris (S.F. Blake) E.E. Schill. \& Panero e com indivíduos jovens de A. santacatarinensis (H. Rob. \& A. J. Moore) E. E. Schill. \& Panero.

Uma amostra de Aldama pilosa depositada em K (da qual S. F. Blake obteve um fragmento para estudos) possui uma etiqueta impressa
'Herb. Reg. Berolinense' com o número 1028 manuscrito. Nessa etiqueta consta a caligrafia de Baker grafando 'Viguiera pilosa Baker'. Porém, o espécime da amostra contém uma pequena etiqueta afixada com uma linha de algodão, com o número 4417. Apesar dessa incompatibilidade numérica, dois fatos levam à proposta de lectotipificação com base no espécime que tem as duas etiquetas, supracitado: ambos os números são citados no protólogo, e durante este trabalho não foram encontrados materiais (exsicatas, esboços ou fotografias) pertencentes ao terceiro número (2225), também mencionado no protólogo.

Aldama robusta (Gardner) E.E. Schill. \& Panero, Bot. J. Linn. 167: 324. 2011. Viguiera robusta Gardner in Hook, London J. Bot. 7: 403. 1848. Viguiera robusta var. genuina S.F. Blake, Contr. Gray Herb. 54: 171. 1918. Rhysolepis robusta (Gardner) H. Rob. \& A.J. Moore, Proc. Biol. Washington 117(7): 431. 2004. Tipo: BRAZIL. GOYAZ: Dry upland campos near San Domingos, V.1840, Gardner 4233 (lectótipo aqui designado: K! - ex Herb. Hookerianum; fotografia do lectótipo: K!, SPF!; isolectótipos: BM!, BR!, G, $\mathrm{GH}-2 \mathrm{x}, \mathrm{K}-2 \mathrm{x}, \mathrm{NY} \mathrm{H}^{*}-2 \mathrm{x}, \mathrm{P}$ !, US*; fotografia do isolectótipo de $\mathrm{G}$ : $\mathrm{F}$ !).

Viguiera scabra Pohl ex Baker in Mart. \& Eichler, Fl. bras. 6(3): 227. 1884, nom. nud. pro syn.

Aldama ovatifolia (Baker) E.E. Schill. \& Panero, Bot. J. Linn. 167: 324. 2011. Viguiera ovatifolia (DC.) Baker in Mart. \& Eichler, Fl. bras. 6(3): 226. 1884. Rhysolepis ovatifolia (Baker) H. Rob. \& A.J. Moore, Proc. Biol. Washington 117(7): 30. 2004. syn. nov. Tipo: [BRASIL. SÃO PAULO]: Habitat in prov. S. Paulo in campis, Herb. Imp. Bras. 410 (holótipo: P!, frag. $\mathrm{GH}$; fotografia do holótipo: P!, SPF!).

Aldama macrocalyx (S. F. Blake) E.E. Schill. \& Panero, Bot. J. Linn. 167: 324. 2011. Viguiera macrocalyx S.F. Blake, Contr. Gray Herb. 54: 171. 1918. Tipo: BRAZIL. Without locality, Pohl 582 (holótipo: K!, frag. G; fotografia do holótipo: K!, SPF!). syn. nov.

Viguiera robusta var. oxylepis S.F. Blake, Contr. Gray Herb. 54: 171. 1918. Tipo: BRASIL. Riedel s.n. (lectótipo aqui designado: $\mathrm{GH}^{*}$ [GH 00014036], isolectótipos: frag. GH, K!, frag. NY*). syn. nov. Aldama radula (Baker) E.E. Schill. \& Panero, Bot. J. Linn. 167: 324. 2011. Viguiera radula Baker in Mart. \& Eichler, Fl. bras. 6(3): 223. 1884. Rhysolepis radula (Baker) H. Rob. \&A. J. Moore, Proc. Biol. Washington 117(7): 431. 2004. Tipo: BRASIL. MINAS GERAIS: Locus minus editis in pascuis et capoeiras ad Caldas 
IV.1865, Regnell I. 190* (lectótipo aqui designado: BR!; fotografia do lectótipo: K!, SPF!; isolectótipos: S!, frag. GH). syn. nov.

Material examinado: BRASIL. BAHIA: São Desidério, área próxima a Roda Velho, após a entrada da Fazenda

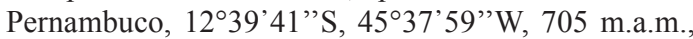
24.IV.1998, fl., R.C. Mendonça et al. 3427 (HEPH, IBGE, RB, US). DISTRITO FEDERAL: Planaltina, rodovia BR $020 \mathrm{~km} \mathrm{16}$, sentido Planaltina - Sobradinho, $15^{\circ} 37^{\prime} 31,8^{\prime \prime}$ 'S, 47²3'32,5”'W, 1139 m.a.m., 16.XII.2001, fr., M. Magenta et al. 336 (K, SPF). GOIÁS: Anápolis,

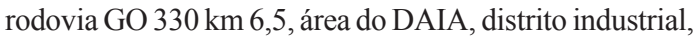
$16^{\circ} 25^{\prime} 51,4^{\prime \prime} \mathrm{S}, 48^{\circ} 52^{\prime} 57,9^{\prime \prime} \mathrm{W}, 1098$ m.a.m., 25.I.2002, fl. e fr., M. Magenta \& J. Magenta 381 (K, SPF). Luziânia, 4.V.1984, fl., T. Naito 20981 (GHSP, SP). Niquelândia, a 3 $\mathrm{km}$ da cidade, 29.IV.1988, fl., R.R. Brooks et al. 238 (UFG). Southernmost ultramafic hill of Tocantine complex., 29.IV.1988, fl. e fr., R.D. Reeves et al. BRASPEX 238 (K). São Gabriel de Goiás, rodovia GO 118, sentido São

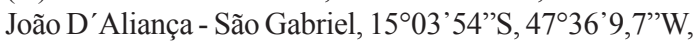
1131 m.a.m., 7.V.2002, fl. e fr., M. Magenta et al. 454 (SPF). município indefinido, Province de Goyaz, Sañ Domingos, V.1840, fl. e fr., G. Gardner 4233 (BM, K, P). MINAS GERAIS: Brumadinho, fazenda da MBR, 15.VI.1989, fl., A.M.G. Anjos et al. 97 (BHCB). Caeté, Serra da Piedade, base da serra, 10.IV.1996, fl., J.A. Lombardi 1256 (BHCB). Camanducaia, estrada para Monte Verde a $19 \mathrm{~km}$ de Camanducaia, 22 ${ }^{\circ} 50^{\prime} 12,4^{\prime}$ 'S, 4606'59”W, 1425 m.a.m., 6.IV.2002, fl. e fr., $M$. Magenta \& J. Magenta 428 (K, SPF). São João Batista da Canastra, Serra da Canastra, estrada para Tapira, ca. 25 km de São João, 1959'53,1'S, 4641'30,1”W, 1285 m.a.m., 18.IV.2003, fl., M. Magenta \& J. Magenta 634 (SPF). Uberaba, rodovia BR $050 \mathrm{~km} \mathrm{118,} \mathrm{12.IV.1996,}$ fl., G. Hatschbach et al. 64552 (CTES, MBM). Unaí, Fazenda São Miguel, Grupo Votarantim, lado oeste da Campina Grande, 950 m.a.m., 23.IV.1992, fl. e fr., B.A.S. Pereira \& D. Alvarenga 2072 (HEPH, IBGE, RB, US); A.F. Regnell I.190 (BR, K, M). PARANÁ: Arapoti, estrada para Ventania, $24^{\circ} 10^{\prime} 31,2^{\prime \prime}$ 'S, 49 $53^{\circ}$ '56,5”'W, 835 m.a.m., 3.IV.2002, fl. e fr., M. Magenta \& J. Magenta 557 (SPF). Jaguariaíva, 19.IV.1910 fl. e fr., Dusén 9723 (K, M). RIO DE JANEIRO: município indefinido, near Rio de Janeiro, XII.1878, fl. e fr., Glaziou 9490 (K). SÃO PAULO: Capão Bonito, rodovia SP $258 \mathrm{~km} 226,5$, sentido Itapeva - Capão Bonito, 2358'42,4’'S, 48²1’39’W, 665 m.a.m., 5.III.2003, fl. e fr., M. Magenta \& J. Magenta 566 (SPF). Cristais Paulista, Estrada Franca-Pedregulho, $20^{\circ} 23^{\prime} 20,1^{\prime \prime}$ S, 47 $7^{\circ} 26^{\prime} 03,5^{\prime}$ 'W, 1020 m.a.m., 1.XI.2001, fl. e fr., M. Magenta \& J. Magenta 296 (SPF). Franco da Rocha, Parque Estadual do Juquery, $23^{\circ} 18^{\prime} \mathrm{S}, 46^{\circ} 48^{\prime} \mathrm{W}$, 900 m.a.m., 16.VI.2002, fl., M. Groppo Jr. et al. 1102 (SPF). São Carlos, Rodovia Washington Luiz, entre Itirapina - São Carlos, 7.III.1997, fr., F.B. Costa et al. 5 (SPFR). São João da Boa Vista, Serra do Caracol, Pico do Gavião, 1666 m.a.m., 10.V.1995, fl. e fr., J.Y. Tamashiro et al. 1053 (SP, SPF, UEC). Sorocaba, Votorantim, 17.IV.1995, fl. e fr., M. Magenta et al. 10 (ESA, HRCB,
SP, SPF, UEC). município indefinido, Province Saint Paulo, fl. e fr., Riedel 338 (P). TOCANTINS: Mateiros, Região do Jalapão, proximidades do Riacho Formiga, fazenda do Sr. Vicente, $10^{\circ} 20^{\prime}$ S, $46^{\circ} 29^{\prime}$ W, 6.V.2001, fl. e fr., P.L. Simpson \& A.B. Sampaio 56 (UB).

Como indica o epíteto específico, trata-se de uma planta robusta, de porte e ramos sempre eretos e capítulos com muitas flores do disco (80-120), com lâmina foliar coriácea, geralmente oval a largamente oval, base arredondada levemente auriculada, e porção superior esparsamente denteada, serreada ou crenada. O capítulo é campanulado a levemente globoso, com invólucro de 1-1,5 cm diâm. Espécie muito comum, ocorrendo no Distrito Federal, Goiás, Tocantins, Bahia, Minas Gerais, São Paulo e Paraná, em campos e cerrados íntegros ou degradados, beira de estradas, rodovias e rios e córregos.

Os espécimes coletados em áreas sujeitas regularmente ao fogo no Distrito Federal e em Goiás, ou mais raramente em Minas Gerais, usualmente apresentam caule e pedúnculos tomentosos, robustos, brácteas involucrais coriáceas, aumento do número de flores do raio, pápus com escamas reduzidas ou sem escamas e tecas geralmente amarelas (as tecas de Aldama usualmente são marrons), o que dificultou a delimitação da espécie. As variações na margem foliar, no tamanho dos capítulos e no número de séries de brácteas involucrais levaram à descrição de Viguiera ovatifolia, V. macrocalyx e $V$. radula, respectivamente; V. robusta var. oxylepis foi descrita com base na forma das brácteas involucrais, caracter também variável.

Embora a etiqueta de identificação manuscrita pelo autor de Viguiera robusta var. oxylepis esteja presente nos materiais dos herbários $\mathrm{GH}$ e $\mathrm{K}$, o primeiro foi escolhido como depositário em virtude de ser onde Blake desenvolveu seus estudos com o gênero. Na lectotipificação de Viguiera radula, não foi encontrada qualquer exsicata nos herbários $\mathrm{K}$ e BM (onde Baker atuava), por isso foi designada a coleta de Regnell depositada em BR com duplicatas em outros acervos.

Aldama squalida (S. Moore) E. E. Schill. \& Panero, Bot. J. Linn. 167: 325. 2011. Viguiera squalida S. Moore, J. Bot. 42: 37: 1904. Rhysolepis squalida (S. Moore) H. Rob. \& A. J. Moore, Proc. Biol. Washington 117(7): 431. 2004. Tipo: BRAZIL. MATO GROSSO: S. Anna da Chapada 20.X.1902, A. Robert 640 (lectótipo aqui designado: BM!; fotografia do lectótipo: K!, SPF!; isolectótipos: frag. e esboço GH, K!). 
Aldama weddellii (S. F. Blake) E.E. Schill. \& Panero, Bot. J. Linn. 167: 325. 2011. Viguiera wedellii Sch. Bip. ex S.F. Blake, Contr. Contr. Gray Herb. 54: 126. 1918. Rhysolepis weddelii (Sch. Bip. ex S.F. Blake) H. Robinson \& A. J. Moore, 1.c.: 432. 2004. Tipo: BRAZIL [GOIÁS]: Between Goyas and Cujaba, XI-XII.1844, Wedell 2911 (holótipo: P!; fotografia do holótipo: F!, K!, SPF!). syn. nov. Material selecionado: BRASIL. GOIÁS: Chapadão do Céu, Parque Nacional de Emas, $17^{\circ} 49^{\prime} \mathrm{S}-18^{\circ} 28^{\prime} \mathrm{S}$,

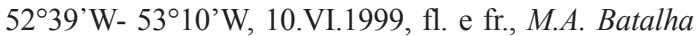
3518 (UEC). Goianira, a $2 \mathrm{~km}$ do Rio Meia Ponte, Fazenda Louzandira, 17.X.1970, fl., J.A. Rizzo \& A. Barbosa 5589 (UFG). Itumbiara, rodovia BR $153 \mathrm{~km} 637$, sentido Itumbiara - Goiânia, 1753'18,8'S, 48¹3'58,9'W, 889 m.a.m., 3.XI.2001, fl. e fr., M. Magenta \& J. Magenta 308 (HUFU, K, SPF, TEX). Mineiros, Morro Vermelho, ca. 10 km Parque Nacional das Emas, 25.XI.1997, fl. e fr., R.C. Forzza et al. 411 (SPF). Mossâmedes, divisa Mossâmedes - Goiás, área da Universidade Federal de Goiás, Serra Dourada, 8.XI.1969, fl., J.A. Rizzo 4546, 4586 (UFG). MATO GROSSO: Alto Paraguai, Serra das Araras - Vão Grande, ca. 27 km S of MT-246, 23.X.1995, fl. e fr., $B$. Dubs 1892 (K, UFMT). Barra do Garças, pé da serra, 4.X.1968, fl., D. Andrade-Lima 271-68 (IPA); Cáceres, Rodovia MT 343, 27.X.1983, fl. e fr., A. Mattos Filho \& N. Saddi 3657 (RB, UFMT). Rondonópolis, Rodovia BR 364, entre kms 348 e 358, Rondonópolis - Alto das Garças, 24.X.1999, F.B. Costa 98 (SPFR). MATO GROSSO DO SUL: Bandeirante, rodovia BR $163 \mathrm{~km} \mathrm{568,} \mathrm{sentido}$ Cuiabá - Bandeirante, rodovia BR 163 km 555,7, sentido Bandeirante - São Gabriel, a 800 m da BR, 1949'51,4'S, 5421'50,9”W, 622 m.a.m., 17.XI.2003, fl. e fr., $M$. Magenta \& T.U. Konno 680 (SPF). Corumbá, Morraria Santa Cruz, Rodovia BR 262 km 743,5, Menck, antena da Embratel, Mineração Corumbense, $19^{\circ} 12^{\prime} 03,7^{\prime \prime}$, 57³5’30,2”W, 1077 m.a.m., 20.XI.2003, fr., M. Magenta \& J. Magenta 686 (SPF); Rio Brilhante, rodovia BR 267, entroncamento, 22.X.1970, fl. e fr., G. Hatschbach 25020, 25040 (MBM, RB); PARANÁ: Laranjeiras do Sul, 7.XI.1963, fl. e fr., E. Perreira \& G. Hatschbach 7737-A (HB, LP, M, MBM, PEL, RB). TOCANTINS: [Araguaína] próximo ao Rio Lontra, na Fazenda Baixa, 9.XI.1973, fl., J.A. Rizzo 9410 (UFG).

Ocorre no Paraguai e no Brasil nos estados de Goiás, Mato Grosso, Mato Grosso do Sul e Tocantins, em matas, cerrados típicos com solo arenoso ou argiloso, campos e em afloramentos rochosos.

É morfologicamente semelhante a Aldama grandiflora e, assim como esta, exibe variações de acordo com o grau de luminosidade: plantas crescendo à sombra apresentam folhas de textura mais fina, formato alongado e cor mais escura, enquanto as expostas ao sol geralmente apresentam um maior número de folhas orbiculares, mais espessas e mais claras. Diferencia-se de $A$. grandiflora por características do invólucro e do pápus (ver comentário em A. grandiflora). A cipsela se assemelha à de $A$. discolor, mas as aristas são geralmente intramarginais (marginais em $A$. discolor) e o indumento do invólucro é diferente: Em A. squalida a face abaxial das brácteas é esparsamente estrigilosa, enquanto em $A$. discolor a face abaxial é vilosa, setosa ou raramente estrigosa. As plantas coletadas em solos contendo grandes quantidades de sedimentos ferríferos nas morrarias da Formação Santa Cruz, ao sul de Corumbá, apresentam-se menores e com folhas mais rígidas. Por outro lado, as plantas da Chapada dos Guimarães em Mato Grosso, podem apresentar folhas muito estreitas [J.U. Santos \& C.S. Rosário 360 e G.T. Prance et al. 18957 (INPA)]; contudo, no herbário $\mathrm{RB}$, há uma duplicata deste último espécime com folhas da forma mais comum na espécie.

Aldama vernonioides (Baker) E.E. Schill. \& Panero, Bot. J. Linn. 167: 325. 2011. Viguiera vernonioides Baker in Mart. \& Eichler, Fl. bras. 6(3): 223.1884. Tipo: [BRASIL. MATO GROSSO]: Habitat in Prov. Mato Grosso, Prope Pouso Alto in via ad urben Cuyabá, s.d., Manso n. 216 (holótipo: BR!; fotografia do holótipo: K!, SPF!).

Aldama hypoleuca (S.F. Blake) E.E. Schill. \& Panero, Bot. J. Linn. 167: 323. 2011. Viguiera hypoleuca S.F. Blake, Contr. Gray Herb. 54: 165.1918. Tipo: BRASIL. MATO GROSSO: Sandy rather grassy open place, Buriti, near Santa Anna da Chapada, sandy rather grassy open places 3.VI.1884, Malme 1658 (lectótipo aqui designado: BM!; fotografia do lectótipo: K!, SPF!, US!; isolectótipos: frag. e esboço GH, R!), syn. nov.

Material selecionado: BRASIL. MATO GROSSO: Chapada dos Guimarães, Santa Ana da Chapada, Cachoeira Véu de Noiva, 15.V.1997, F.E.F. de Souza 4 (UFMT); Diamantino, $42 \mathrm{~km}$ de Diamantino, em direção a Nobres, Serra do Tombador, $14^{\circ} 37^{\prime} \mathrm{S}, 56^{\circ} 15^{\prime} \mathrm{W}, 400$ m.a.m., 17.V.1997, fr., V.C. Souza et al. 16024 (ESA); São Vicente, São José da Serra, rodovia BR 364 km 319, entre Jaciara

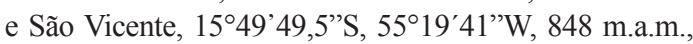
27.V.2002, fl. e fr., M. Magenta \& J. Magenta 460 (SPF).

Planta resinífera que ocorre apenas no sul do Mato Grosso, na Chapada dos Guimarães e suas proximidades.

Espécie muito semelhante a Aldama gardneri, difere desta por apresentar pelas raízes adventícias sem tuberosidade, folhas com lâmina geralmente oblongo-lanceolada, a maioria dos capítulos com apenas três séries de brácteas involucrais, as flores menores e em menor número (flores do raio ca. 
8, com 6-10 × 2-2,5 mm, flores do disco 45-85, corola 4-4,5 mm alt.) ausência de tricomas nos lobos das flores do disco, antera de base curtamente sagitada, estilete com alargamento basal levemente cônico e anteras terminando na base do colar da antera ou abaixo. A. gardneri possui raízes adventícias tuberosas na porção mediana, folhas com lâmina oblonga a largamente oblonga, elíptica, oval-lanceolada ou raramente oval, capítulos com brácteas involucrais em $4-5$ séries, flores do raio 12-16, com corola 9-12 × 2-3 mm de alt., flores do disco $80-150$, corola $6-7 \mathrm{~mm}$ alt., face externa estrigilosa, antera de base curtamente sagitada, terminando acima ou na base do colar da antera e estilete com alargamento basal fusiforme.

O material depositado no BM foi escolhido como lectótipo de $V$. hypoleuca por conter a etiqueta manuscrita por Blake.

\section{Agradecimentos}

Agradecemos aos curadores dos herbários visitados ou contatados a disponibilização das coleções e obras raras e envio de imagens de tipos e, em especial, ao Dr. David J. Nicholas Hind do Royal Botanic Garden - Kew, as discussões nomenclaturais. Aos pesquisadores Claudio Augusto Mondin e Fernando Batista da Costa, o auxílio em trabalhos de campo e à Fundação de Amparo a Pesquisa do Estado de São Paulo (FAPESP - Projeto Temático no 2010/51454-3) o suporte financeiro concedido. O segundo autor agradece ao CNPq o apoio por meio de bolsa de Produtividade em Pesquisa.

\section{Referências}

Baker, J.G. 1884. Compositae IV: Helianthoideae. In: Martius, C.F.P. \& Eichler, A.W. (eds.). Flora brasiliensis. Monachii, Lipsiae, Frid. Fleischer. Vol. 6, pars 3, Pp. 135-268, tabs. 45-75.

Blake, S.F. 1917. New and noteworth Compositae, chiefly Mexican. Contributions from the Gray Herbarium of Harvard University 52: 16-39.

Blake, S.F. 1918. A revision of the genus Viguiera. Contributions of Gray Herbarium of Harvard University 54: 1-205.

Bombo, A.; Oliveira, T. S.; Oliveira, A.S.S.; Rheder, V.L.G.; Magenta, M.A.G. \& Appezzato-da-Glória, B. 2012. Anatomy and essential oils from aerial organs in three species of Aldama (AsteraceaeHeliantheae) that have a difficult delimitation. Australian Journal of Botany (Print) 60: 632-642.

Hassler, E. 1916. Repertorium Specierum Novarum Regni Vegetabilis. Centralblatt für Sammlung und Veroffentlichung von Einzeldiagnosen neuer Pflanzen. Friedrich Fedde, Berlin.

Herter, W.G. \& Rambo, B. 1953. Nas pegadas dos Naturalistas Sellow \& Saint-Hillaire (Itinera Sellowio-Hilariana). Revista sudamericana de botánica 10: 61-100.

Karis, P.O. 1993. The Heliantheae sensu latu (Asteraceae), clades and classification. Plant Systematics and Evolution 186: 139-195.

La Llave, P. 1824. Aldama. In: La Llave \& Lex (eds.). Novorum vegetabilium descriptiones $1.14 \mathrm{p}$.

Magenta, M.A.G. 2006. Viguiera Kunth (Asteraceae, Heliantheae) na América do Sul e sistemática das espécies do Brasil. Tese de Doutorado. Universidade de São Paulo, São Paulo. 353p.

Magenta, M.A.G.; Pirani, J.R. \& Mondin, C.A. 2010. Novos táxons e combinações de Viguiera Kunth (Asteraceae-Heliantheae) no Brasil. Rodriguésia 61: 01-11.

Mondin, C.A. 2006. Tipificação de Viguiera megapotamica Malme (Asteraceae). Hoehnea 33: 403-405.

Robinson, H. 1977. Studies in Heliantheae (Asteraceae) VIII. Notes on genus and species limits in the genus Viguiera. Phytologia 36: 201-215.

Robinson, H. 1984. Studies in the Heliantheae(Asteraceae). XXXIX. New species of Aspilia from Brazil. Phytologia 56: 262-286.

Robinson, H. \& King, R.M. 1977. Eupatorieae Systematic review. In: Hoody, V.H.; Harborne, J.B. \& Turner B.L. (eds.). The biology and chemistry of the compositae. Vol. 1. Academic Press, London. Pp. 437-485.

Robinson, H. \& Moore, A.J. 2004. New species and new combinations in Rhysolepis (Heliantheae Asteraceae). Proceedings of the Biological Society of Washington 117: 423-446.

Schilling, E.E. \& Jansen, R.K. 1989. Restriction fragment analysis of chloroplast DNA and the systematics of Viguiera and related genera (AsteraceaeHeliantheae). American Journal of Botany 76: 1769-1778.

Schilling, E.E. \& Panero, J.L. 1991. Evidence for a close relationship between Iostephane and Viguiera (Asteraceae-Heliantheae). American Journal of Botany 78: 1054-1062.

Schilling, E.E. \& Panero, J.L. 1996a. Relationships in Heliantheae subtribe Helianthinae based on chloroplast DNA restriction site analysis. In: Hind, D.J. \& Beentje, H.J. (eds.). Compositae: systematics proceedings of the International Compositae Conference. Vol. 1. Royal Botanic Gardens, Kew. Pp. 361-376.

Schilling, E.E. \& Panero, J.L. 1996b. Phylogenetic reticulation in subtribe Helianthinae. American Journal of Botany 83: 939-948. 
Schilling, E.E. \& Panero, J.L. 2002. A revised classification of subtribe Helianthinae (AsteraceaeHeliantheae). I. Basal lineages. Botanical Journal of the Linnean Society 140: 65-76.

Schilling, E.E. \& Panero, J.L. 2010. Transfers to Simsia and description of Davilanthus, a new genus of Asteraceae (Heliantheae). Brittonia 62: 309-320.
Schilling, E.E. \& Panero, J.L. 2011. A revised classification of subtribe Helianthinae (Asteraceae: Heliantheae) II. Derived Lineages. Botanical Journal of the Linnean Society 167: 311-331.

White, I.C. 1908. Relatório final da Comissão de Estudos das Minas de Carvão de Pedra do Brasil. DNPM. Rio de Janeiro, 1988. Parte II (ed. Fac-similar). Pp. 301-617. 